\title{
Interplay between Synchronization of Multivesicular Release and Recruitment of Additional Release Sites Support Short- Term Facilitation at Hippocampal Mossy Fiber to CA3 Pyramidal Cells Synapses
}

\author{
Simon Chamberland, Alesya Evstratova, and Katalin Tóth \\ Quebec Mental Health Institute, Department of Psychiatry and Neuroscience, Laval University, Quebec City, Quebec, Canada, G1J 2G3
}

Synaptic short-term plasticity is a key regulator of neuronal communication and is controlled via various mechanisms. A well established property of mossy fiber to CA3 pyramidal cell synapses is the extensive short-term facilitation during high-frequency bursts. We investigated the mechanisms governing facilitation using a combination of whole-cell electrophysiological recordings, electrical minimal stimulation, and random-access two-photon microscopy in acute mouse hippocampal slices. Two distinct presynaptic mechanisms were involved in short-term facilitation, with their relative contribution dependent on extracellular calcium concentration. The synchronization of multivesicular release was observed during trains of facilitating EPSCs recorded in $1.2 \mathrm{~mm}$ external $\mathrm{Ca}^{2+}\left(\left[\mathrm{Ca}^{2+}\right]_{\mathrm{e}}\right)$. Indeed, covariance analysis revealed a gradual augmentation in quantal size during trains of EPSCs, and application of the low-affinity glutamate receptor antagonist $\gamma$-D-glutamylglycine showed an increase in cleft glutamate concentration during paired-pulse stimulation. Whereas synchronization of multivesicular release contributed to the facilitation in $1.2 \mathrm{mM}\left[\mathrm{Ca}^{2+}\right]_{e}$, variance-mean analysis showed that recruit-

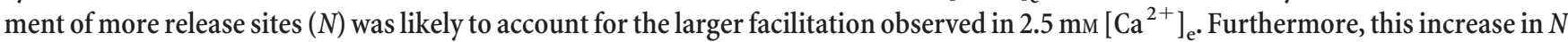
could be promoted by calcium microdomains of heterogeneous amplitudes observed in single mossy fiber boutons. Our findings suggest that the combination of multivesicular release and the recruitment of additional release sites act together to increase glutamate release during burst activity. This is supported by the compartmentalized spatial profile of calcium elevations in boutons and helps to expand the dynamic range of mossy fibers information transfer.

Key words: mossy fiber; multivesicular release; presynaptic calcium; short-term facilitation

\section{Introduction}

Hippocampal mossy fiber (MF) axons innervate CA3 pyramidal cells via complex presynaptic terminals comprising a large number of release sites (Amaral and Dent, 1981; Chicurel and Harris, 1992; Acsády et al., 1998; Rollenhagen et al., 2007). Although the initial release probability of glutamate at this synapse is low (Jonas et al., 1993; von Kitzing et al., 1994; Lawrence et al., 2004), postsynaptic responses show a remarkable degree of short-term facilitation during repetitive activation of MF inputs (Regehr et al., 1994; Salin et al., 1996; Toth et al., 2000; Henze et al., 2002;

\footnotetext{
Received Feb. 27, 2014; revised June 7, 2014; accepted June 27, 2014

Author contributions: S.C. and K.T. designed research;S.C., A.E., and K.T. performed research; S.C., A.E., and K.T. analyzed data; S.C. and K.T. wrote the paper.

This work was supported by a Canadian Institutes of Health Research operating grant (K.T.), a Natural Sciences and Engineering Research Council of Canada scholarship (S.C.), and a Centre thématique de recherche en neurosciences fellowship (A.E.). We thank Dr. Yves De Koninck for providing access to the acousto-optic deflector-based two-photon imaging system, Dr. Stéphane Dieudonné (Paris, France) for advice with RAMP and two-photon calcium imaging, and Benjamin Mathieu (Paris, France) for expert help and development with the imaging software.

The authors declare no competing financial interests.

Correspondence should be addressed to Dr. Katalin Tóth, Quebec Mental Health Institute, Department of Psychiatry and Neuroscience, Faculty of Medicine, Laval University, 2601 chemin de la Canardière, Quebec City, Quebec, Canada, G1J 2G3. E-mail: toth.katalin@crulrg.ulaval.ca.

DOI:10.1523/JNEUROSCI.0847-14.2014

Copyright $\odot 2014$ the authors $\quad 0270-6474 / 14 / 3411032-16 \$ 15.00 / 0$
}

Lawrence et al., 2004). MFs are also referred to as conditional "detonator" synapses because a single granule cell is capable of triggering action potentials (APs) in postsynaptic pyramidal cells during increased activity (Henze et al., 2002). These data demonstrate that the probability of neurotransmitter release from large MF terminals can vary widely depending on the activity levels of granule cells. Increases in the probability of neurotransmitter release can be explained by an increase in the number of vesicles available for release, a change in the mode of release, or by altered calcium dynamics (Schneggenburger et al., 2002; Burnashev and Rozov, 2005; Scott and Rusakov, 2006). In this report, we investigate the mechanisms responsible for the increased mobilization of release-ready vesicles in MF terminals during short bursts, leading to short-term facilitation.

The strength of synaptic responses can be altered by the amount of neurotransmitter released from presynaptic terminals and is determined by the number of functional connections and the release probability. In addition, changes in the number of vesicles that are released per AP can also alter synaptic strength. Several studies demonstrated that central synapses release multiple vesicles under physiological conditions (Tong and Jahr, 1994; Auger et al., 1998; Wadiche and Jahr, 2001; Oertner et al., 2002; Foster et al., 2005; Watanabe et al., 2005; Christie and Jahr, 2006). 
Multivesicular release is primarily influenced by the release probability $(p)$ at the time of release (Christie and Jahr, 2006). This suggests that any alteration in the $p$, such as it occurs within stimulus trains, could potentially influence the number of vesicles that are released per APs (Satake et al., 2012).

Endogenous $\mathrm{Ca}^{2+}$ buffers and $\mathrm{Ca}^{2+}$ release from internal stores influences frequency-dependent facilitation of MF-evoked signals (Scott and Rusakov, 2006; Scott et al., 2008; Vyleta and Jonas, 2014). Loose coupling between calcium channels and calcium sensors endows endogenous $\mathrm{Ca}^{2+}$ buffers with the capacity to decrease initial release probability. However, during train or short burst stimulations similar to the typical firing pattern of granule cells in vivo (Pernía-Andrade and Jonas, 2014), progressive saturation of endogenous $\mathrm{Ca}^{2+}$ buffers contributes to the rapid increase in intrabouton $\mathrm{Ca}^{2+}$ concentration. In addition, calcium release from internal stores further increases presynaptic calcium transients at this synapse (Scott and Rusakov, 2006; Vyleta and Jonas, 2014).

Overall, our findings reveal that MF terminals can dramatically increase the amount of glutamate released during repetitive firing by switching from univesicular to multivesicular release and an increase in the number of functional release sites. Alterations in local calcium dynamics support both mechanisms leading to the formation of heterogeneous calcium domains in a single terminal.

\section{Materials and Methods}

Slice preparation. All experiments involving animals were performed according to Animal Protection Committee of Laval University guidelines. Hippocampal slices $(300 \mu \mathrm{m})$ were obtained from P17-P25 wild-type C57BL/6 mice of either sex. Animals were anesthetized with isoflurane, and the brain was rapidly extracted and submerged in ice-cold oxygenated artificial CSF (ACSF) containing the following (in mM): $87 \mathrm{NaCl}, 25$ $\mathrm{NaHCO}_{3}, 2.5 \mathrm{KCl}, 1.25 \mathrm{NaH}_{2} \mathrm{PO} 4,1 \mathrm{MgCl}_{2}, 0.5 \mathrm{CaCl}_{2}, 25$ glucose, and 75 sucrose, pH 7.4 (330 mOsm). After dissection of the brain to best preserve the MFs (Bischofberger et al., 2006), slices were cut on a vibratome (VT1000S; Leica) and moved to a heated $\left(32^{\circ} \mathrm{C}\right)$ and oxygenated solution containing the following (in mM): $124 \mathrm{NaCl}, 25 \mathrm{NaHCO}_{3}, 2.5 \mathrm{KCl}, 1.2$ $\mathrm{MgCl}_{2}, 2.5 \mathrm{CaCl}_{2}$, and 10 glucose, $\mathrm{pH} 7.4$ (300 mOsm). Slices were allowed to recover for at least $30 \mathrm{~min}$ before beginning experiments and were kept at room temperature for additional use.

Electrophysiological recordings. Slices were transferred to a recording chamber under an upright microscope equipped with a $40 \times$ objective and continuously perfused $(2 \mathrm{ml} / \mathrm{min})$ with heated $\left(32-34^{\circ} \mathrm{C}\right)$ ACSF containing the following (in $\mathrm{mm}$ ): $124 \mathrm{NaCl}, 25 \mathrm{NaHCO}_{3}, 2.5 \mathrm{KCl}, 1.2$ $\mathrm{MgCl}_{2}, 2.5 \mathrm{CaCl}_{2}, 10$ glucose, and 0.001 bicuculline methiodide, $\mathrm{pH} 7.4$ (oxygenated with $95 \% \mathrm{O}_{2}$ and $5 \% \mathrm{CO}_{2}, 300 \mathrm{mOsm}$ ). For experiments performed in the low calcium condition, $\mathrm{CaCl}_{2}$ was adjusted to $1.2 \mathrm{~mm}$ and $\mathrm{MgCl}_{2}$ was increased to $2.5 \mathrm{~mm}$ to keep the concentration of divalent ions constant. Whole-cell voltage-clamp recordings were performed at $-70 \mathrm{mV}$ from visually identified CA3 pyramidal cells with glass electrodes containing the following (in mM): $130 \mathrm{CsMeSO}_{3}, 10$ HEPES, 4 $\mathrm{NaCl}, 2 \mathrm{Mg}_{2} \mathrm{ATP}, 0.3 \mathrm{NaGTP}, 10$ phosphocreatine, and 0.6 EGTA, pH 7.3 (295 mOsm); or $120 \mathrm{~K}$-gluconate, $20 \mathrm{KCl}, 10 \mathrm{HEPES}, 2 \mathrm{MgCl}_{2}, 2$ $\mathrm{Mg}_{2} \mathrm{ATP}, 0.3 \mathrm{NaGTP}, 7$ phosphocreatine, and 0.6 EGTA, pH 7.2 (295 $\mathrm{mOsm}$ ). MFs were stimulated electrically in stratum lucidum with a glass micropipette connected to a constant-current stimulus isolator (A360; WPI). The pipette was moved until fast and facilitating EPSCs were found. The stimulation intensity was adjusted to obtain both successes and failures. MF origin of recorded input was confirmed by applying $\left(2 S, 1^{\prime} R, 2^{\prime} R, 3^{\prime} R\right)$-2-(2,3-dicarboxycyclopropyl)-glycine (DCG-4; $\left.1 \mu \mathrm{M}\right)$ at the end of the experiments. Cells in which EPSCs were inhibited by at least $80 \%$ were kept for analysis. Series resistance was not compensated $(8-22 \mathrm{M} \Omega)$ and was monitored with $-10 \mathrm{mV}$ pulses delivered in the end of each sweep. Cells with changes $>20 \%$ in series resistance during recordings were discarded. Electrophysiological signal was acquired with an Axopatch 200B or 200A (Molecular Devices), low-pass filtered at 2
$\mathrm{kHz}$, and digitized at $10 \mathrm{kHz}$ with a Digidata $1322 \mathrm{~A}$ or $1440 \mathrm{~A}$ (Molecular Devices). The signal was recorded using the Clampex 9.0 or 11.0 software (Molecular Devices).

The following pharmacological compounds were used in the experiments: $\gamma$-D-glutamylglycine ( $\gamma$-DGG; 0.5 and $2 \mathrm{~mm}$; Abcam), cyclopiazonic acid (CPA; $30 \mu \mathrm{M}$; Sigma-Aldrich), thapsigargin (1 $\mu \mathrm{M}$; Sigma-Aldrich), EGTA-AM (100 $\mu \mathrm{M}$; Anaspec), DCG-4 (1 $\mu \mathrm{M}$; Tocris/R\&D Systems), bicuculline methiodide ( $1 \mu \mathrm{M}$; Sigma-Aldrich), and threo- $\beta$-benzyloxyaspartic acid (TBOA; $10 \mu \mathrm{M}$; Tocris/R\&D Systems).

Random-access two-photon microscopy. A custom-built random-access multiphoton system (RAMP) identical to the system described by Otsu et al., (2008) was used in these experiments (Kaluti System). The RAMP setup was equipped with a titanium:sapphire pulsed laser (Chameleon Ultra; repetition rate, $80 \mathrm{MHz}$; pulse width, $140 \mathrm{fs}$; average power, $>3.5$ $\mathrm{W}$; Coherent) tuned at 720 or $800 \mathrm{~nm}$. Acousto-optic deflectors (A-A Opto-Electronics) provided fast redirection of the laser beam in the $x y$ dimensions. The laser was focused through a high numerical aperture water-immersion $25 \times$ objective (numerical aperture 0.95 ; Leica) under an upright microscope. Transmitted photons were collected through an oil condenser (numerical aperture 1.4). The detection pathway consisted of a low-pass $720 \mathrm{~nm}$ filter and a $580 \mathrm{~nm}$ dichroic mirror (Semrock) to separate the signal in "green" and "red" channels. Photons were bandpass filtered $(500-560 \mathrm{~nm})$ in both the green and red channels (595-665 $\mathrm{nm})$. Photons were detected with two cooled external AsGaP (H7422P40) photomultiplier tubes (Hamamatsu). The lasers and the imaging systems were controlled using a homemade software written in Labview (Otsu et al., 2008).

Two-photon glutamate uncaging and calcium imaging. Individual neurons were visually targeted for patch-clamp recordings using Dodt scanning gradient contrast. For glutamate uncaging experiments, the morphological dye Alexa Fluor-594 (20-40 $\mu \mathrm{m}$; Life Technologies) was added to the recording solution and diffused passively in the recorded neurons for $10 \mathrm{~min}$ before scanning at $800 \mathrm{~nm}$ to acquire morphological images of the cell. Thorny excrescences were identified as large complex spines on the initial portion of CA3 pyramidal cell dendrites in the stratum lucidum. 4-Methoxy-7-nitroindolinyl-glutamate (MNI-Glu; 10 $\mathrm{mm}$; Tocris/R\&D Systems) was applied locally at $\sim 20 \mu \mathrm{m}$ from the spine of interest. Oxygenated ACSF containing MNI-Glu was loaded into a broken patch pipette (opening of $\pm 10 \mu \mathrm{m}$ ) and was puffed locally ( $2 \mathrm{psi}$, 5-15 ms) with a PicoSpritzer (Parker Instrumentation). Ten points were selected for uncaging close to the complex spine to mimic glutamate release from MF. The laser wavelength was switched to $720 \mathrm{~nm}$ for MNIGlu uncaging. Glutamate was uncaged for $100 \mu$ s on each point, and the laser was rapidly redirected between points $(6.5 \mu \mathrm{s})$ for a total stimulation time of $<1.1 \mathrm{~ms}$. Five and ten uncaging-evoked EPSCs were generated at 20 or $50 \mathrm{~Hz}$ in bursts, repeated at $0.1 \mathrm{~Hz}$.

For presynaptic calcium imaging, whole-cell current-clamp recordings were obtained from granule cells with a K-based pipette solution exempt of EGTA and supplemented with Alexa Fluor-594 (0.04 mM) and Oregon Green BAPTA-1 (OGB-1; 0.05 mM). To avoid perturbing physiological intracellular calcium dynamics, a low concentration of the calcium indicator was used (Goldberg and Yuste, 2004). APs were evoked by short (2 ms) current injections (1-2 nA) in the recording pipette. Granule cells were passively filled with Alexa Fluor-594 and OGB-1 in the whole-cell configuration for $1 \mathrm{~h}$ before starting experiments. Granule cell axons were followed in CA3 using the fluorescence emitted by Alexa Fluor-594. The success rate of recording from a granule cell with an intact axon reaching the CA3 was 38\%. Large axonal MF boutons were identified in CA3 based on their peculiar morphology. The $z$ position was adjusted to be in the middle portion of the structure. Twenty to forty points were positioned on the bouton of interest. Single points were illuminated for 20-50 $\mu$ s, and the time for the laser to switch between each point was $6.5 \mu$ s (Otsu et al., 2008). Using such settings, the acquisition rate ranged from 450 to $2000 \mathrm{~Hz}$. Both green and red fluorescence were acquired at the same time. Single and bursts of five APs at $50 \mathrm{~Hz}$ were evoked after a baseline period. Optical signals were recorded with custom-built software written in Labview.

Data analysis. Electrophysiological data was analyzed using Clampfit 10.2 software (Molecular Devices) and Igor Pro 6.3 (Wavemetrics). The 
rise time of EPSCs was measured as the $20-80 \%$ rise time. The decay $\tau$ of EPSCs was measured from 100 to $37 \%$. The paired-pulse ratio (PPR) was measured by dividing the average amplitude of the responses to the second stimulus by the average amplitude of the first response. The coefficient of variation $(\mathrm{CV})$ was measured as the SD of EPSCs $(\sigma)$ divided by the mean $(\mu)$ :

$$
\mathrm{CV}=\sigma / \mu
$$

For nonstationary variance-mean analysis, the variance of EPSCs was plotted against the peak amplitude, and the data were fitted with a linear function constrained to the origin (Eq. 1) or with a compound binomial function (Eq. 2):

$$
\begin{gathered}
\sigma^{2}=Q \bar{x} \\
\sigma^{2}=\left(1+\mathrm{CV}^{2}\right) Q \bar{x}-\left(\bar{x}^{2} / n\right),
\end{gathered}
$$

in which $\sigma^{2}$ is the variance, $Q$ is the quantal size, $n$ is the number of release sites, and $\bar{x}$ is the average EPSC amplitude (Lawrence et al., 2004). Based on our measurements, CV was set at 0.45 . To measure the $Q_{\text {initial }}$, the points corresponding to the first two stimuli on the variance-mean plot were fit with a straight line. Covariance analysis was performed on the same trains of EPSCs (Scheuss and Neher, 2001; Scheuss et al., 2002). The covariance (Cov) between two successive EPSCs in the train was calculated using the following formula (Scheuss et al., 2002):

$$
\operatorname{Cov}_{i, i+1}=\frac{1}{R-1} \sum_{r=1}^{R-1}\left(I_{i, r}-I_{i, r+1}\right)\left(I_{i+1, r}-I_{i+1, r+1}\right) / 2
$$

where $I$ is the EPSC amplitude, $\bar{I}$ is the mean of EPSCs for a given stimulus number, $i$ is the EPSC position in the train, $R$ is the total number of train, and $r$ is the train number. From this, the quantal size was estimated using the covariance using the following formula (Scheuss et al., 2002):

$$
Q_{i}=\frac{\operatorname{Var}_{i}}{\bar{I}_{i}}-\frac{\operatorname{Cov}_{i, i+1}}{\bar{I}_{i+1}} .
$$

Calcium signals were analyzed offline in Igor Pro 6.3. Changes in fluorescence intensity $(\Delta G / G)$ were calculated as $\left(G-G_{0}\right) / G_{0}$, where $G$ is the green fluorescence intensity, and $G_{0}$ is the baseline fluorescence (averaged over $50-100 \mathrm{~ms})$. Similarly, $\Delta G / R$ was calculated as $\left(G-G_{0}\right) / R$ and represents the change in OGB-1 fluorescence normalized to Alexa Fluor594 fluorescence, averaged over the whole recording duration $(R)$. Amplitudes of the calcium transients evoked by one AP were measured at the peak. Sizes of boutons were measured in Image (NIH). All bars show SE, unless otherwise stated (see Fig. 4 and corresponding data). Paired and unpaired Student's $t$ tests were used, with ${ }^{\star} p<0.05$, ${ }^{\star *} p<0.01$, and ${ }^{\star * *} p<0.001$.

\section{Results}

\section{Two mechanisms support short-term facilitation at MF-CA3 synapses}

In a behaving animal, a typical granule cell discharges infrequently but fires APs in high-frequency bursts (Csicsvari et al., 2003; Pernía-Andrade and Jonas, 2014). MF-CA3 synapses show markedly high-frequency-dependent facilitation both in vitro (Jung and McNaughton, 1993; Urban et al., 2001) and in vivo (Klausnitzer and Manahan-Vaughan, 2008). We intended to investigate the mechanisms that allow sustained short-term facilitation at MF-CA3 synapses by varying the external $\mathrm{Ca}^{2+}$ concentration to explore the effect of release probability. As expected, raising the external $\mathrm{Ca}^{2+}$ concentration from 1.2 to 2.5 mM sharply reduced the failure rate of evoked EPSCs (43.2 \pm 10.3 to $5.2 \pm 2.5 \%$; $p<0.0001)$ and significantly increased their potency ( $68 \pm 7.1$ to $249.8 \pm 30 \mathrm{pA} ; p<0.0001)$. During bursts of stimuli at high frequency (five pulses at $50 \mathrm{~Hz}$ ), EPSCs were strongly facilitated in both conditions $\left(1.2 \mathrm{mM} \mathrm{Ca}^{2+}, 68 \pm 7.1\right.$ to $216.8 \pm 32.3 \mathrm{pA} ; 2.5 \mathrm{mM} \mathrm{Ca}^{2+}, 249.8 \pm 30$ to $849.7 \pm 108.5 \mathrm{pA}$;
Fig. $1 A, B 1)$. The rise time of EPSCs evoked in $2.5 \mathrm{~mm} \mathrm{Ca}^{2+}$ became progressively slower during the trains (first EPSC, $0.59 \pm$ $0.04 \mathrm{~ms}$; fifth EPSC, $0.70 \pm 0.04 \mathrm{~ms} ; n=11 ; p=0.0013$ ), whereas the rise times of EPSCs evoked in $1.2 \mathrm{~mm} \mathrm{Ca}^{2+}$ were significantly faster in the end of the trains (first EPSC, $1.07 \pm 0.20 \mathrm{~ms}$; fifth EPSC, $0.73 \pm 0.08 \mathrm{~ms} ; n=8 ; p=0.038$; Fig. 1B2). However, the decay $\tau$ was not changed (Fig. 1B3). Surprisingly, our data showed that, even though the facilitation reached similar levels after five pulses (percentage of first stimulus, $329 \pm 49 \%$ in 1.2 $\mathrm{mM} \mathrm{Ca}^{2+}$ and $358 \pm 48 \%$ in $\left.2.5 \mathrm{mM} \mathrm{Ca}^{2+} ; p>0.5\right)$, the time course was significantly different in the two conditions. Although the amplitude increased linearly with the stimulus number in 2.5 $\mathrm{mm} \mathrm{Ca}^{2+}\left(r^{2}=0.983\right)$, a power law $(3.34 \pm 0.2)$ better described the facilitation observed in $1.2 \mathrm{mM} \mathrm{Ca}^{2+}$ (Fig. 1B4). Accordingly, the PPR for two adjacent stimuli varied in different directions. In the presence of $2.5 \mathrm{mM} \mathrm{Ca}^{2+}$, the PPR was lowest for the last pair of stimuli but highest for the last pair of stimuli in conditions of low release probability (Fig. 1C1).

Measuring the CV of EPSC peak amplitude revealed a significant increase in $\mathrm{CV}$ during brief trains of stimuli recorded in 1.2 $\mathrm{mM} \mathrm{Ca}^{2+}$ (first stimulus, $0.46 \pm 0.06$; fourth stimulus, $0.63 \pm$ $0.06 ; p=0.0067)$. In contrast, the $\mathrm{CV}$ was significantly decreased during bursts of EPSCs in $2.5 \mathrm{mM} \mathrm{Ca}^{2+}$ (first stimulus, $0.44 \pm$ 0.4 ; fifth stimulus, $0.24 \pm 0.2 ; p=0.0002$; Fig. $1 C 2$ ). To visualize and characterize these variations, we performed a $\mathrm{CV}$ analysis (Faber and Korn, 1991). Plotting the ratio of $\mathrm{CV}^{-2}$ as a function of the PPR clearly showed segregated data points during the train. Individual points fell on the identity line in $2.5 \mathrm{mM} \mathrm{Ca}^{2+}$, whereas data points obtained in $1.2 \mathrm{~mm} \mathrm{Ca}^{2+}$ were found on or under the $y=1$ line (Fig. 1D). Therefore, two different mechanisms contributed to short-term facilitation. According to classical interpretation of the CV analysis (Faber and Korn, 1991), our results reveal that short-term facilitation in elevated external calcium should be mediated by an increase in the number of release sites $(N)$, whereas it would likely involve an increase in the quantal size ( $Q$ ) in conditions of lower release probability.

Increasing extracellular calcium could potentially raise the general excitability of the hippocampal slice or alter the properties of the AP (Schneggenburger et al., 1999), thereby directly interfering with our analysis. We addressed this possibility in two independent ways. First, we explored whether the two mechanisms could coexist in the same extracellular calcium concentration. To test this hypothesis, we recorded long trains of EPSCs (10 stimuli, $20 \mathrm{~Hz}$ ) in $1.2 \mathrm{~mm}$ extracellular $\mathrm{Ca}^{2+}$. EPSCs were readily facilitated during the train (first EPSC, $80.6 \pm 12.7 \mathrm{pA}$; 10th EPSC, $509.4 \pm 77.9 \mathrm{pA} ; n=10 ; p=0.0002$; Fig. $2 A, B$, top). Additionally, the CV of EPSCs was increased in the beginning of the train before declining significantly below the initial value by the 10th stimulus (first EPSC, $0.47 \pm 0.04 ; 10$ th EPSC, $0.3 \pm 0.04$; $n=10$; $p=0.0072$; Fig. $2 B$, bottom). Performing CV analysis on this dataset clearly showed two distinct components, with the first four initial points constrained around the $y=1$ line, and the last four points increasing linearly (Fig. 2C). A shift occurred on average at the fifth stimulus in the train, followed by a short plateau (Fig. 2C). However, it is important to note that the threshold for the switch varied across cells, indicating that it may depend on the intraterminal calcium concentration, reflected in the probability of release. Furthermore, this short plateau may represent the combination of both mechanisms contributing to short-term facilitation at the same time. Therefore, these data show that the two mechanisms can cooperate and be recruited sequentially in physiological conditions to mediate short-term facilitation at MF-CA3 pyramidal cell synapses. 
A

C1

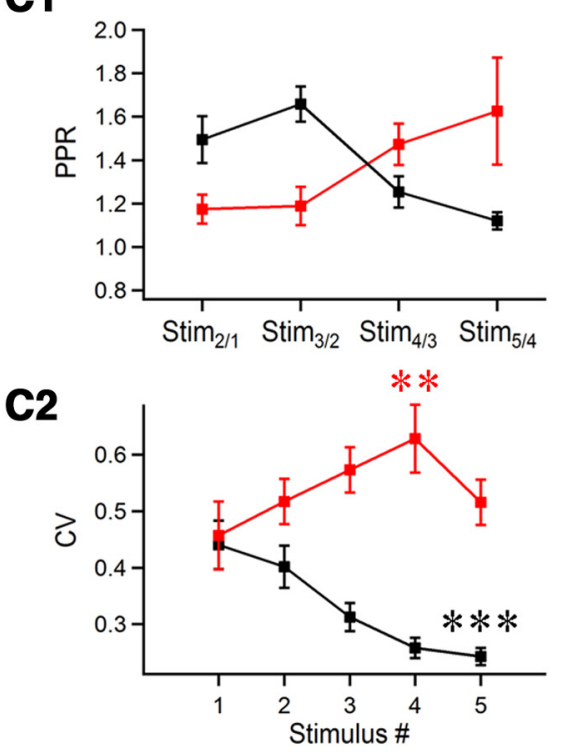

B1
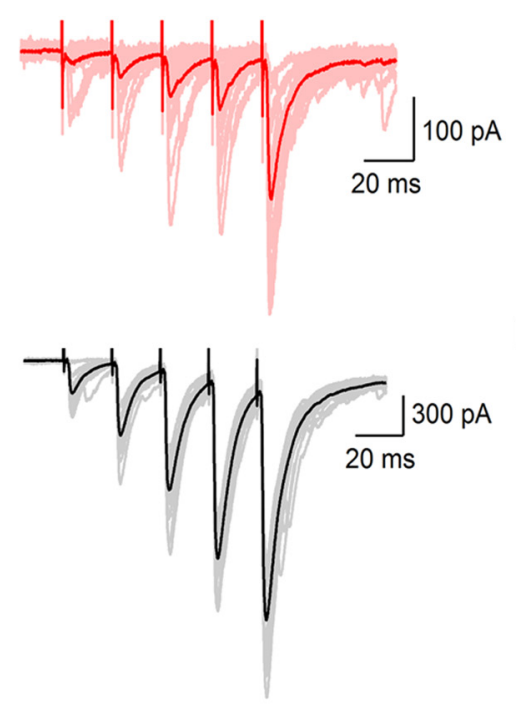

\section{B3}

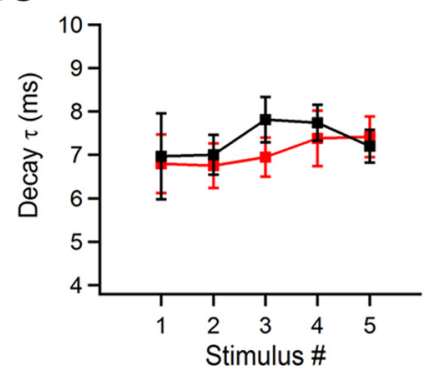

B2
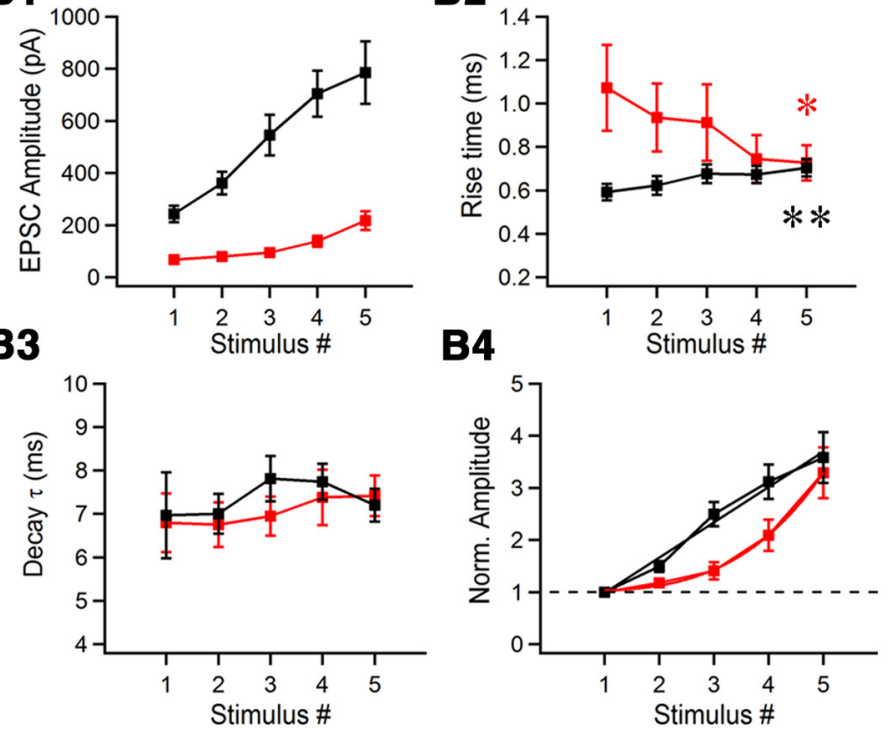

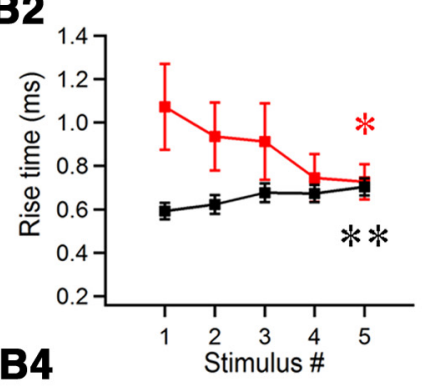

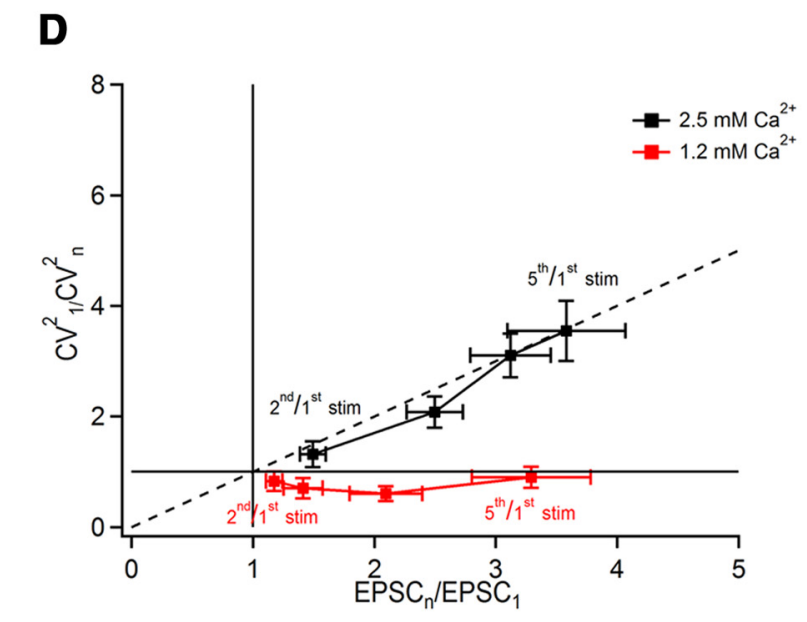

Figure 1. Two mechanisms are involved in short-term facilitation at MF-CA3 synapses. $A$, Representative examples ( 20 consecutive traces with overlaid average) of MF-evoked EPSC trains ( 50 $\mathrm{Hz}, 5$ stimuli) recorded in CA3 pyramidal cells in the presence of $1.2 \mathrm{~mm}$ (red) and $2.5 \mathrm{~mm}$ (black) external calcium. B1, Summary graph of EPSC amplitude shows the facilitation of EPSCs at two different release probabilities. B2, Graph of EPSC rise time as a function of stimulus number shows the gradual decrease in EPSCS rise time in low extracellular calcium $\left({ }^{*} p<0.05\right.$, 1st EPSC vs 5 th EPSC) and a slight increase in conditions of elevated extracellular calcium (**p $<0.01$, 1st EPSC vs 5th EPSC). B3, Decay $\tau$ of EPSCs was constant during trains of EPSCs in both conditions. B4, Normalized EPSC amplitude as a function of stimulus number demonstrates that short-term facilitation of EPSCs does not occur at the same rate at different release probabilities. C1, Accordingly, the PPR of two adjacent stimuli changed in opposite directions during trains of EPSCs in both conditions. C2, The CV was significantly increased during trains evoked in $1.2 \mathrm{~mm}$ extracellular calcium $\left({ }^{* *} p<0.01\right.$, 1st EPSC vs 4th EPSC), whereas a decrease was observed in elevated $\mathrm{Ca}^{2+}$ conditions $\left({ }^{* * *} p<0.001,1\right.$ st EPSC vs 5 th EPSC). D, CV ${ }^{2}$ ratios within subsequent events in the train plotted against normalized EPSC amplitudes. This analysis illustrates the changes observed in CV and PPR during trains of facilitating EPSCs, revealing the contribution of two different mechanisms to short-term facilitation.

Second, we reasoned that, if the observed switch in mechanism depends on the level of calcium invading the presynaptic terminal, then buffering intracellular calcium while leaving extracellular calcium unchanged should replicate the switch in mechanism observed in low and elevated calcium conditions (Zucker and Regehr, 2002). To investigate this possibility, we took advantage of the membrane-permeable form of the slow calcium chelator EGTA (EGTA-AM) that de-esterifies and accumulates to millimolar concentrations in the terminals but remains inert in the extracellular space (Atluri and Regehr, 1996; Hefft and Jonas, 2005). EPSCs were evoked at $20 \mathrm{~Hz}$ for $0.5 \mathrm{~s}$ in $2.5 \mathrm{mM} \mathrm{Ca}^{2+}$ concentration and in the presence of EGTA
(EGTA-AM; $100 \mu \mathrm{M}$ ), which markedly reduced the size of all EPSCs in the train $(62.1 \pm 5 \%$ of control for the first EPSC in the train; $p<0.001$; Fig. 2D; Castillo et al., 1996; Salin et al., 1996; Tzounopoulos et al., 1998). In line with previous studies, shortterm facilitation was also strongly attenuated by EGTA-AM (Castillo et al., 1996; Salin et al., 1996; Blatow et al., 2003), but clear short-term facilitation was still present (Fig. 2E). Additionally, after application of EGTA-AM, CV analysis showed a switch in the mechanism recruited for short-term facilitation of EPSCs, qualitatively identical to the difference observed between $1.2 \mathrm{mM}$ $\mathrm{Ca}^{2+}$ and $2.5 \mathrm{mM} \mathrm{Ca}^{2+}$ (Fig. $2 F$ ). Indeed, the data points moved from the identity line to the $y=1$ line. Furthermore, the 
A

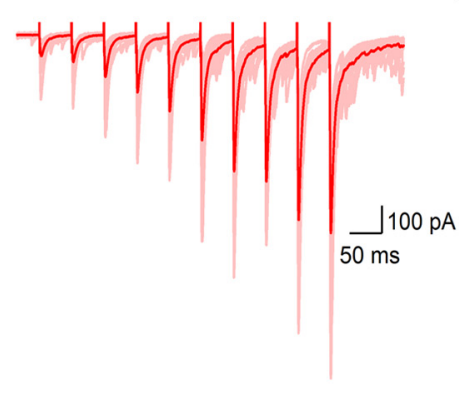

D
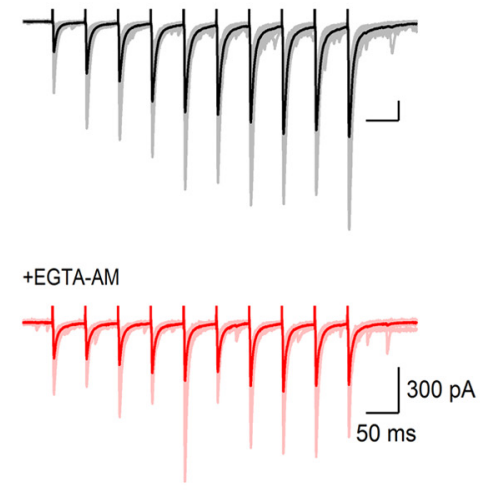

B
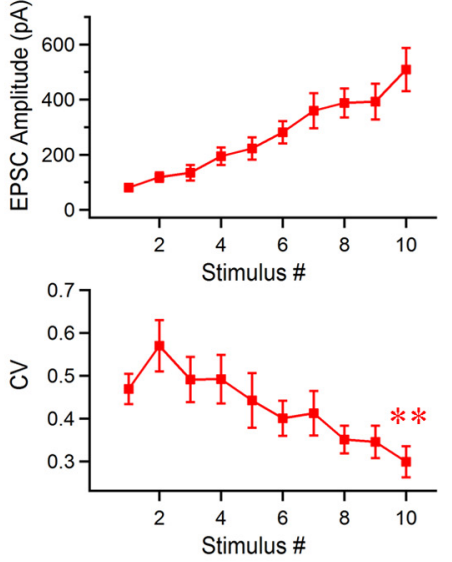

E
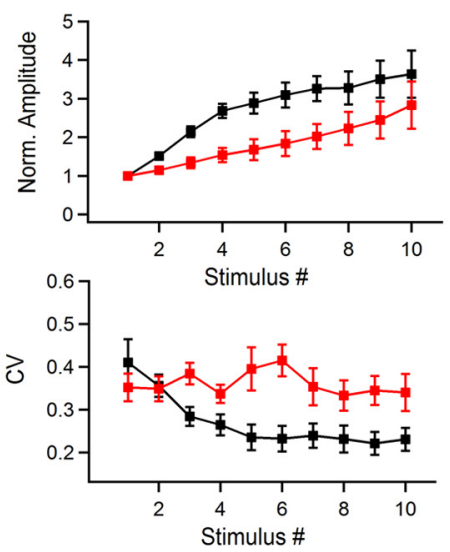

C

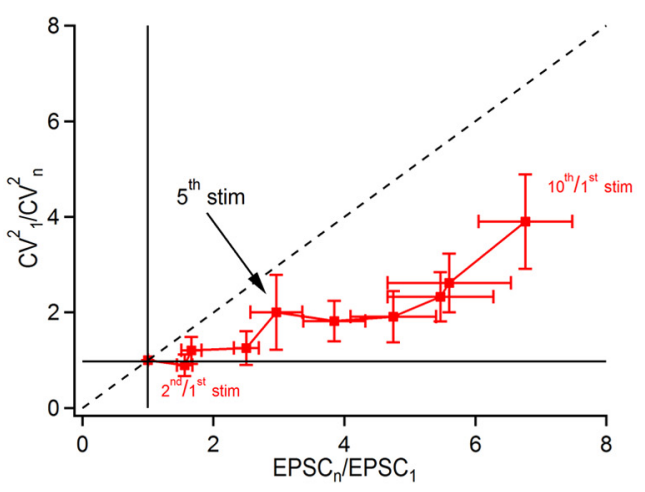

$\mathbf{F}$

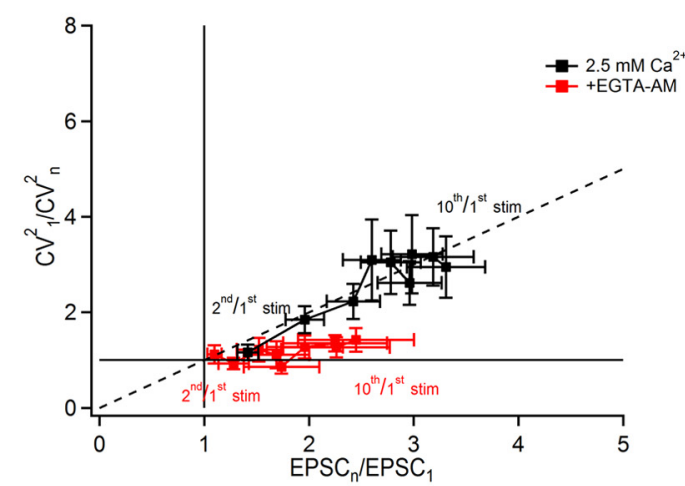

Figure 2. Short-term facilitation involves two components during prolonged activity and requires an increase in intracellular calcium. $\boldsymbol{A}$, Representative examples of MF-evoked EPSCS (10 stimuli, $20 \mathrm{~Hz}$ ) recorded in a CA3 pyramidal cell (25 consecutive traces and the average) in $1.2 \mathrm{~mm}$ external $\mathrm{Ca}^{2+}$. B, Graphs of EPSC amplitude and CV as a function of stimulus number show the initial increase in CV followed by a gradual decrease during trains of facilitating EPSCS $\left({ }^{* *} p<0.01\right.$, 1st EPSC vs 10th EPSC). C, CV analysis reveals that the two distinct mechanisms are successively involved in short-term facilitation. The arrow points to the fifth stimulus, in which a change in data distribution is observed and corresponds to a shift in the facilitation mechanism. $D$, EPSCs recorded in $2.5 \mathrm{~mm}$ external $\mathrm{Ca}^{2+}$ (black traces) and in the presence of the membrane-permeant slow calcium chelator EGTA-AM (100 $\mu \mathrm{M}$, red traces). E, Graphs of normalized EPSC amplitude and CV during the trains. Note that the gradual decrease in $\mathrm{CV}$ is abolished in the presence of EGTA-AM. $F$, $\mathrm{CV}$ analysis in $2.5 \mathrm{~mm}$ external $\mathrm{Ca}^{2+}$ and in the presence of EGTA-AM reveals a shift in the mechanism for short-term facilitation.

EGTA-AM data reveal that, although it could suppress the increase in $N$, as shown by $\mathrm{CV}$ analysis, buffering intracellular calcium was insufficient to completely abolish short-term facilitation at MFCA3. Indeed, a large fraction of short-term facilitation mediated by an increase in $Q$ remained. These results suggest that the mechanism supporting an increase in $N$ is loosely coupled to the source of calcium entry in the presynaptic terminal (Borst and Sakmann, 1996; Meinrenken et al., 2002; Eggermann et al., 2012; Vyleta and Jonas, 2014), although there is a tight coupling between the calcium entry site and the mechanism involved in the increase in $Q$ because it was unaffected in the presence of EGTA-AM (Hefft and Jonas, 2005; Bucurenciu et al., 2008).

\section{Short-term facilitation is of presynaptic origin}

Our results indicate that short-term facilitation at MF-CA3 pyramidal cells first involves an increase in $Q$, followed by an increase in $N$. Classically, an increase in $N$ would be expected to be of presynaptic origin. For example, the recruitment of additional release sites would be attributed to the presynaptic terminal and could occur through elevated residual calcium, recruitment of additional calcium sources, or activation of autoreceptors (Contractor et al., 2001; Schmitz et al., 2001; Pinheiro et al., 2007; Kwon and Castillo, 2008). Conversely, an increase in the quantal size would better be explained by changes at the postsynaptic site. For instance, local dendritic depolarization could relieve the magnesium blockade of NMDA receptors in the postsynaptic domain and allow their activation, therefore contributing to short-term facilitation by increasing the conductance evoked by neurotransmitter quanta. Although short-term facilitation was reported to be presynaptic at MF-CA3 synapses (Salin et al., 1996), we investigated whether the postsynaptic domain could also contribute to facilitation of EPSCs. To explore whether short-term facilitation can be observed at the postsynaptic site at MF-CA3 pyramidal cell synapses, we adapted a two-photon glutamate uncaging approach. This method allows highly focalized activation of postsynaptic glutamate receptor without interference from presynaptic release mechanisms (Denk et al., 1990; Callaway and Katz, 1993). To simulate glutamate release from MFs, two-photon glutamate uncaging was performed on 10 points for $100 \mu$ s each around a thorny excrescence on the apical dendrite of CA3 pyramidal cells in stratum lucidum (Fig. 3A). Single-spine photostimulation generated large EPSCs (potency, $60.3 \pm 11.4 \mathrm{pA} ; n=4$ cells). Interestingly, no significant facilitation of EPSCs was observed, independently of the uncaging pulses frequency $(20 \mathrm{~Hz}$ : fifth/first EPSC, $117.4 \pm 8.9 \%, n=3$ cells; $50 \mathrm{~Hz}$ : fifth/first EPSC, $90.9 \pm 4.7 \%, n=4$ cells; Fig. $3 B, C)$. 
A

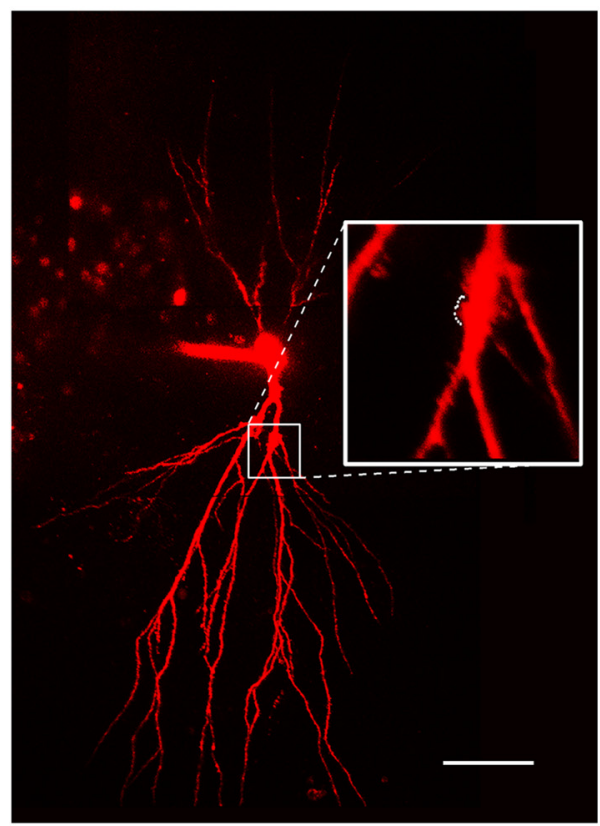

B1

$20 \mathrm{~Hz}$

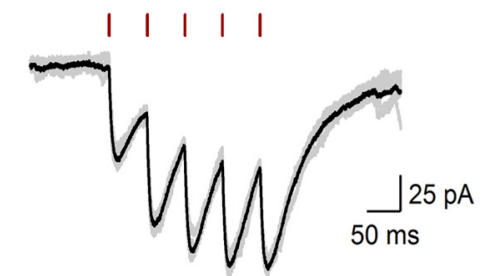

C1

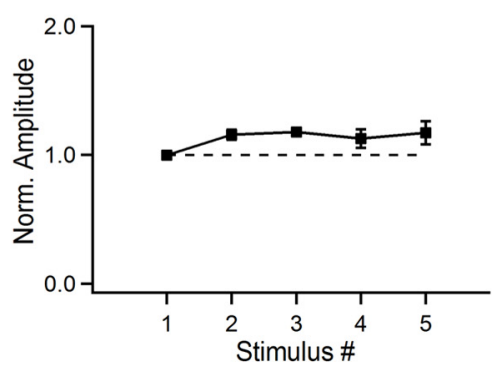

B2

$50 \mathrm{~Hz}$ | 1 | 1 |
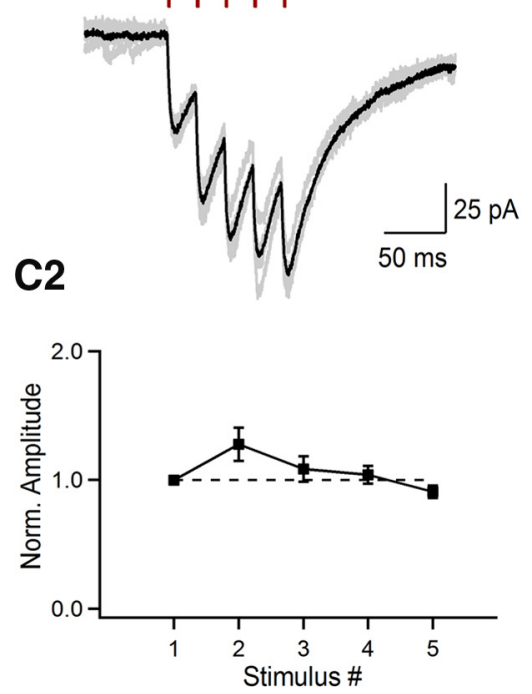

Figure 3. Mechanisms involved in short-term facilitation are of presynaptic origin. A, Two-photon Z-stack maximal projection of a CA3 pyramidal cell filled with Alexa Fluor-594 obtained after the recordings. Inset shows expanded thorny excrescence in which fast multipoint two-photon glutamate uncaging was performed (white points; total uncaging time, $1.1 \mathrm{~ms}$ ). Scale bar, $50 \mu \mathrm{m}$. $\boldsymbol{B}$, Examples of uncaging-evoked EPSCs (5 traces and their average) triggered at $20 \mathrm{~Hz}(\mathbf{B}$ ) and $50 \mathrm{~Hz}$ (B2). Red lines indicate the uncaging pulse. C, Summary graphs of normalized uncaging-evoked EPSCS amplitude time course showing no changes in amplitude during trains of uncaging pulses at $20 \mathrm{~Hz}$ (C1) and $50 \mathrm{~Hz}$ (C2).

Indeed, the amplitude of EPSCs remained stable in trains compared with electrically evoked EPSCs that always demonstrated extensive short-term facilitation (Figs. 1, 2). By selectively bypassing the presynaptic terminal using two-photon glutamate uncaging, our results demonstrate the absence of short-term facilitation mediated at the postsynaptic domain. Therefore, both mechanisms involving increases in $Q$ and $N$ during high-frequency bursts at MF-CA3 pyramidal cells synapses are presynaptic.

\section{Gradual increase in $Q$ during trains in conditions of low release probability}

Presynaptic mechanisms provide a fast and efficient means to expand the range over which single MF-CA3 synapses can support neurotransmission from granule to CA3 pyramidal cells during short bursts of high-frequency activity. Accordingly, we aimed to quantify how short-term facilitation is shaped by changes in $Q$ and $N$. To measure quantal parameters, we performed nonstationary variance-mean analysis in conditions of low and elevated extracellular $\mathrm{Ca}^{2+}$ and compared the quantal size and the number of release sites. The first and last EPSCs recorded in small bursts of five stimuli at $50 \mathrm{~Hz}$ were stable over time in both conditions (Fig. $4 A, B$ ). Fitting the initial portion of the variance-mean plot with a linear function in low and high release probability conditions revealed a markedly lower $Q_{\text {initial }}$ in $1.2 \mathrm{mM} \mathrm{Ca}^{2+}\left(Q_{1,2}, 31.8 \pm 2.7 \mathrm{pA} ; n=9\right)$ than in $2.5 \mathrm{mM} \mathrm{Ca}^{2+}$ $\left(Q_{1,2}, 50.4 \pm 0.9 \mathrm{pA} ; n=10\right.$; Fig. $\left.4 C\right)$. Based on this result and on $\mathrm{CV}$ analysis indicating a change in $Q$ during the trains in $1.2 \mathrm{~mm}$ external $\mathrm{Ca}^{2+}$, we thought that the quantal size could change during the train in low release probability conditions. Therefore, we added subsequent stimuli one at a time to the fitted portion of the data to investigate this possibility. Our results show a gradual increment of the quantal size during the train in $1.2 \mathrm{~mm}$ extracellular $\mathrm{Ca}^{2+}\left(Q_{1,2}, 31.8 \pm 2.7 \mathrm{pA} ; Q_{1-3}, 39.4 \pm 4.1 \mathrm{pA} ; Q_{1-4}, 52.3 \pm\right.$ $6.1 \mathrm{pA} ; Q_{1-5}, 48.8 \pm 4 \mathrm{pA} ; n=9$; Fig. $4 C$ ) but not in $2.5 \mathrm{~mm}$ extracellular $\mathrm{Ca}^{2+}\left(Q_{1,2}, 50.4 \pm 0.9 \mathrm{pA} ; Q_{1-3}, 52.2 \pm 0.9 \mathrm{pA} ; Q_{1-4}\right.$, $49.3 \pm 1.6 \mathrm{pA} ; Q_{1-5}, 45.6 \pm 2.4 \mathrm{pA} ; n=10$; Fig. $\left.4 C\right)$. A limitation of this approach is that the linear fitting procedure includes previous EPSCs, and it could potentially underestimate measurements of $Q$ later in the train (Scheuss et al., 2002). Therefore, to provide a more accurate measure of how $Q$ changes during the train for a given stimulus, we used a covariance analysis on the same dataset (Scheuss and Neher, 2001; Scheuss et al., 2002). This analysis confirmed the significant and gradual increase in $Q$ during the train in low release probability conditions $\left(Q_{1,2}, 24 \pm 6.8\right.$ $\left.\mathrm{pA} ; Q_{4,5}, 50 \pm 9.7 \mathrm{pA} ; n=9 ; p=0.02\right)$. However, in agreement with our previous findings, $Q$ was unchanged during the train in $2.5 \mathrm{~mm}$ external $\mathrm{Ca}^{2+}\left(Q_{1,2}, 54.9 \pm 6.3 \mathrm{pA} ; Q_{4,5}, 51.3 \pm 8.5 \mathrm{pA}\right.$; $n=10 ; p=0.74$; Fig. $4 E$ ).

$\mathrm{CV}$ analysis indicates that a change in the number of release sites is associated with short-term facilitation in conditions of elevated release probability. To address whether $N$ is increased in $2.5 \mathrm{~mm}$ extracellular $\mathrm{Ca}^{2+}$, we recorded EPSCs in response to longer bursts ( 10 stimuli, $50 \mathrm{~Hz}$; Fig. $4 F$ ) to further increase the release probability to approximate $N$. Because the variance-mean data approached and reached a plateau, it could be fitted with a compound binomial function (Reid and Clements, 1999; Clements and Silver, 2000). The number of release sites was remarkably higher in $2.5 \mathrm{mM} \mathrm{Ca}^{2+}(16.2 \pm 2.5$ release sites $)$ than in 1.2 $\mathrm{mM} \mathrm{Ca}^{2+}(6.8 \pm 2$ release sites; Fig. $4 G)$. This shows that additional release sites are recruited to mediate neurotransmission in higher release probability conditions.

Altogether, these data indicate that a gradual increase in the quantal size is responsible for the facilitation of EPSCs in $1.2 \mathrm{~mm}$ $\mathrm{Ca}^{2+}$ and that the number of release sites is greatly increased in $2.5 \mathrm{mM} \mathrm{Ca}^{2+}$. Accordingly, short-term facilitation is shaped by a gradual increase in $Q$ during trains in conditions of low release probability, whereas $Q$ is already at maximal levels in conditions of $2.5 \mathrm{~mm}$ external $\mathrm{Ca}^{2+}$. Furthermore, the number of release 
A
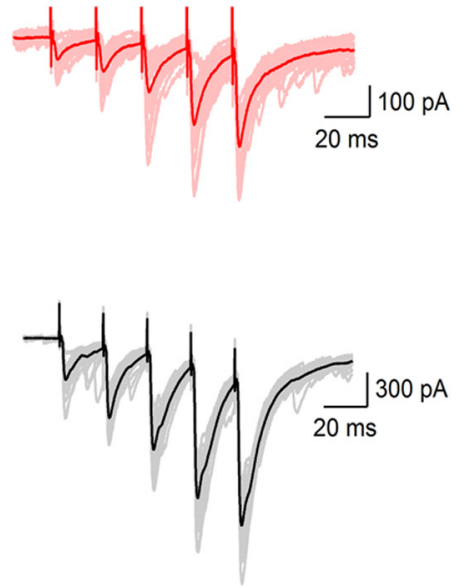

D
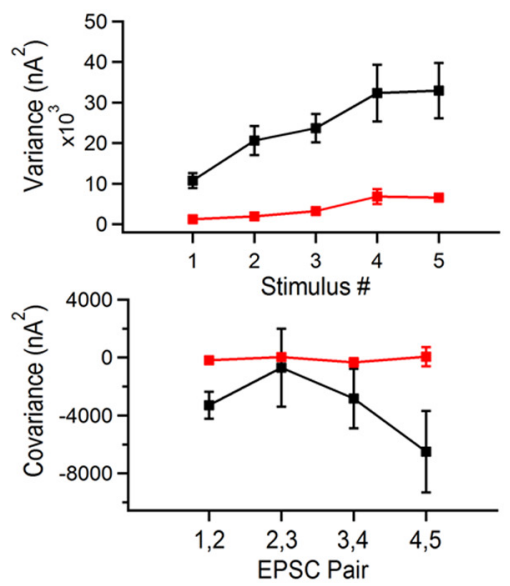

B
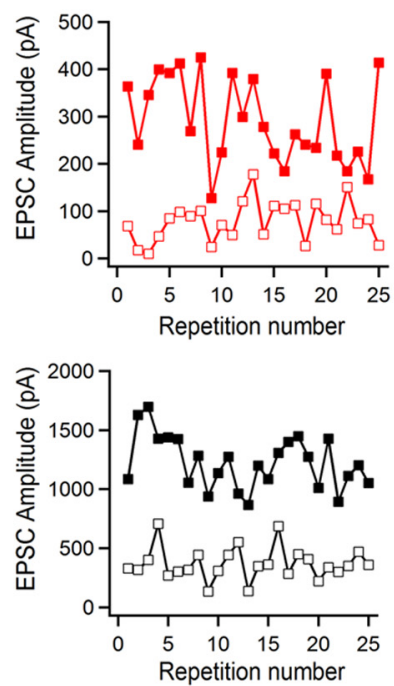

E
C

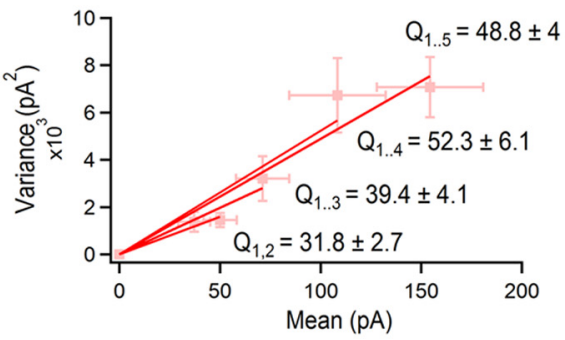

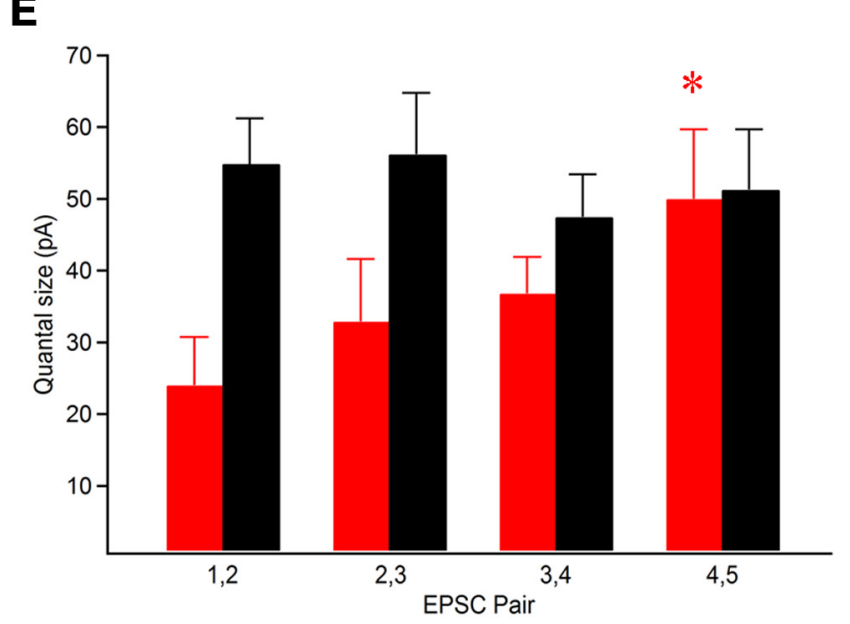

F
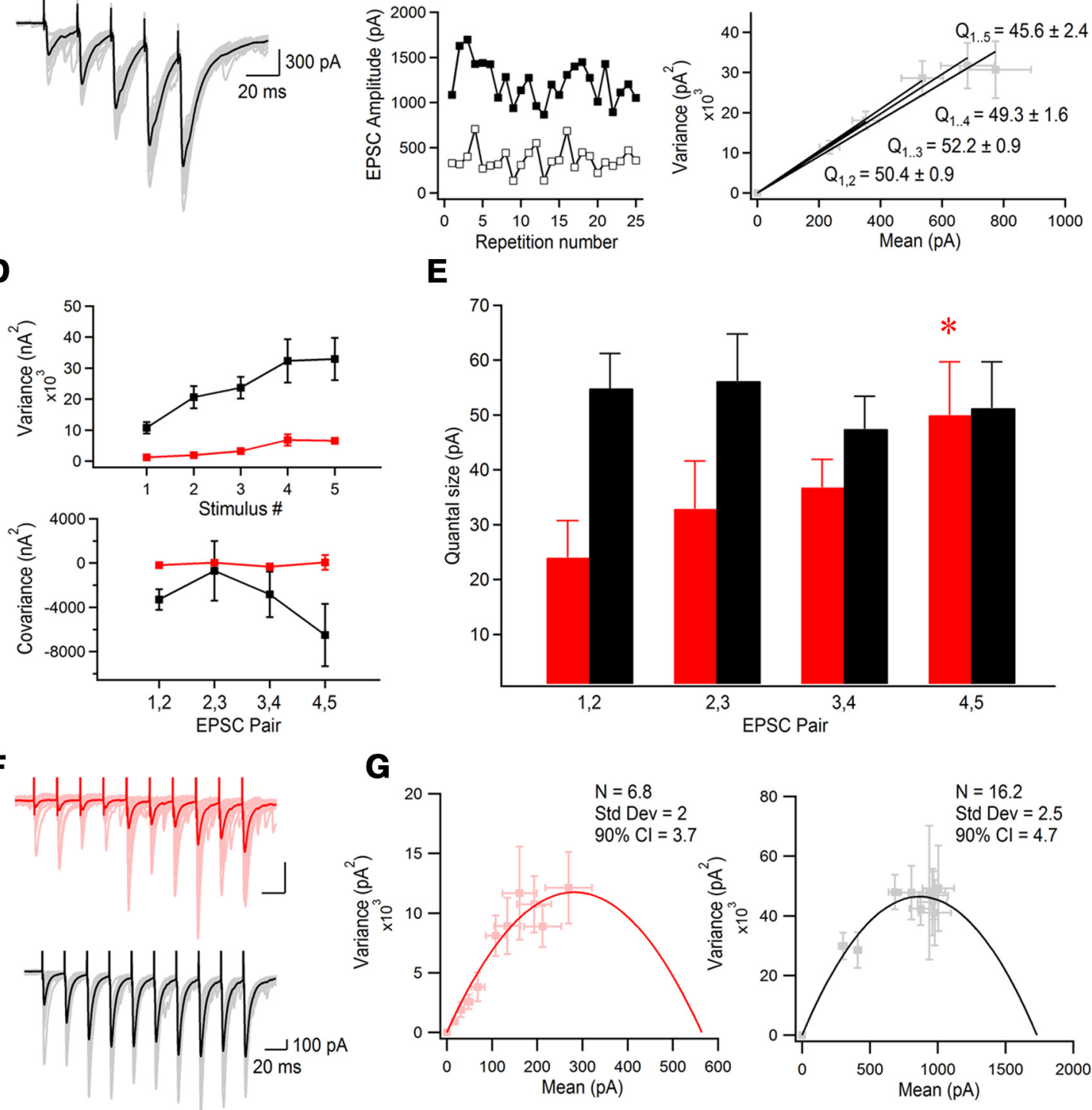

G

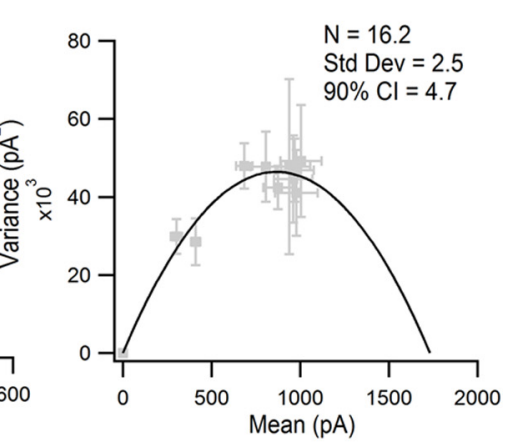

Figure 4. Increases in the number of release sites and in quantal size. $A$, Examples of EPSC trains recorded in $1.2 \mathrm{~mm}$ (red) and $2.5 \mathrm{~mm}$ (black) external $\mathrm{Ca}^{2+}$ used to perform nonstationary variance-mean analysis and covariance analysis. $\boldsymbol{B}$, Amplitudes of the first (open circles) and fifth (filled circles) EPSCs as a function of repetition number in low (top) and normal (bottom) release probability conditions show the stability of the recordings. C, Nonstationary variance-mean analysis in conditions of low (red) and elevated (black) external calcium performed on the variance-mean plots obtained from trains of EPSCs for all cells. Fitting the data with a linear function yielded the quantal sizes associated with the stimulus number in conditions of low and elevated external $\mathrm{Ca}^{2+}$. Error bars indicate SD. D, Variance and covariance of EPSCs during trains as a function of stimulus number. $\boldsymbol{E}$, Summary bar graph of quantal size measured with covariance analysis as a function of stimulus number indicates a progressive increase in quantal size in conditions of $1.2 \mathrm{~mm}$ external $\mathrm{Ca}^{2+}\left({ }^{*} p<0.05\right.$, EPSC $_{1,2}$ vs EPSC $\left._{4,5}\right)$ and a constant quantal size in $2.5 \mathrm{~mm}$ external $\mathrm{Ca}^{2+}$. $\boldsymbol{F}$, Representative examples of EPSCs recorded in two conditions of release during trains of 10 stimuli at $50 \mathrm{~Hz}$. G, Variance-mean plots of EPSCs amplitude. The data were fitted with a compound binomial function to measure the number of release sites active in both conditions. Error bars represent SD.

sites mediating neurotransmitter release is increased by more than twofold in elevated calcium conditions, thereby providing a means for increased neurotransmission during short-term facilitation at MF-CA3 synapses.
Increased cleft glutamate concentration during facilitation in conditions of low release probability

The gradual increase in $Q$ observed in conditions of low release probability could be mediated by the liberation of additional ves- 
A
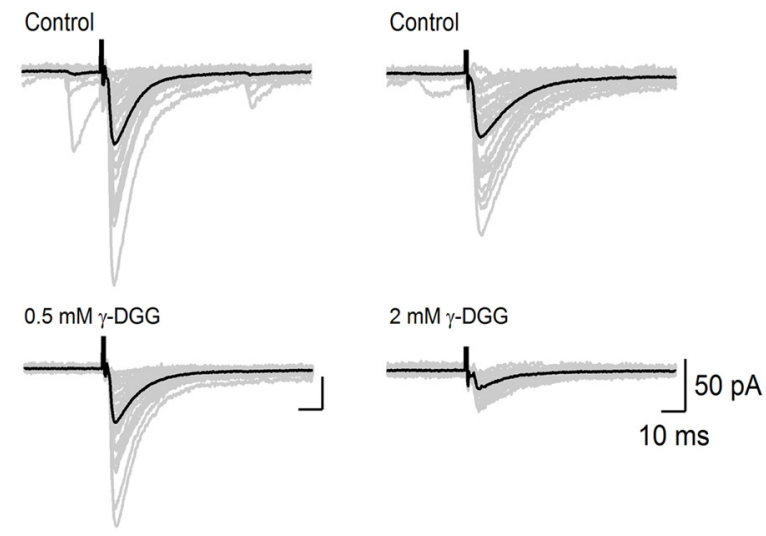

B

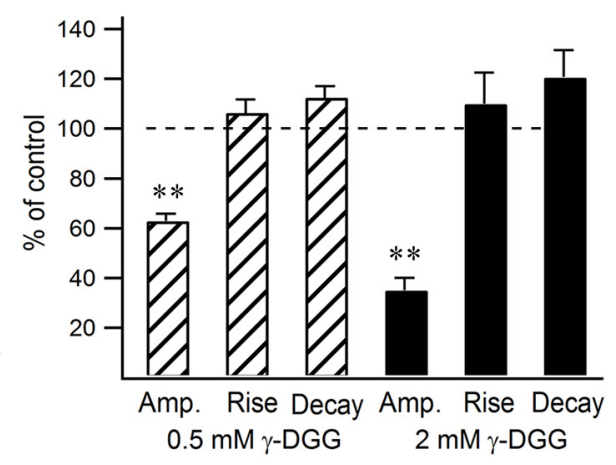

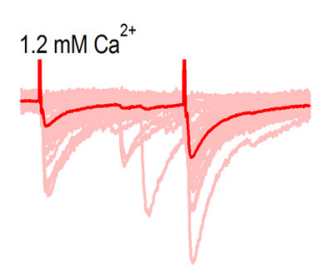
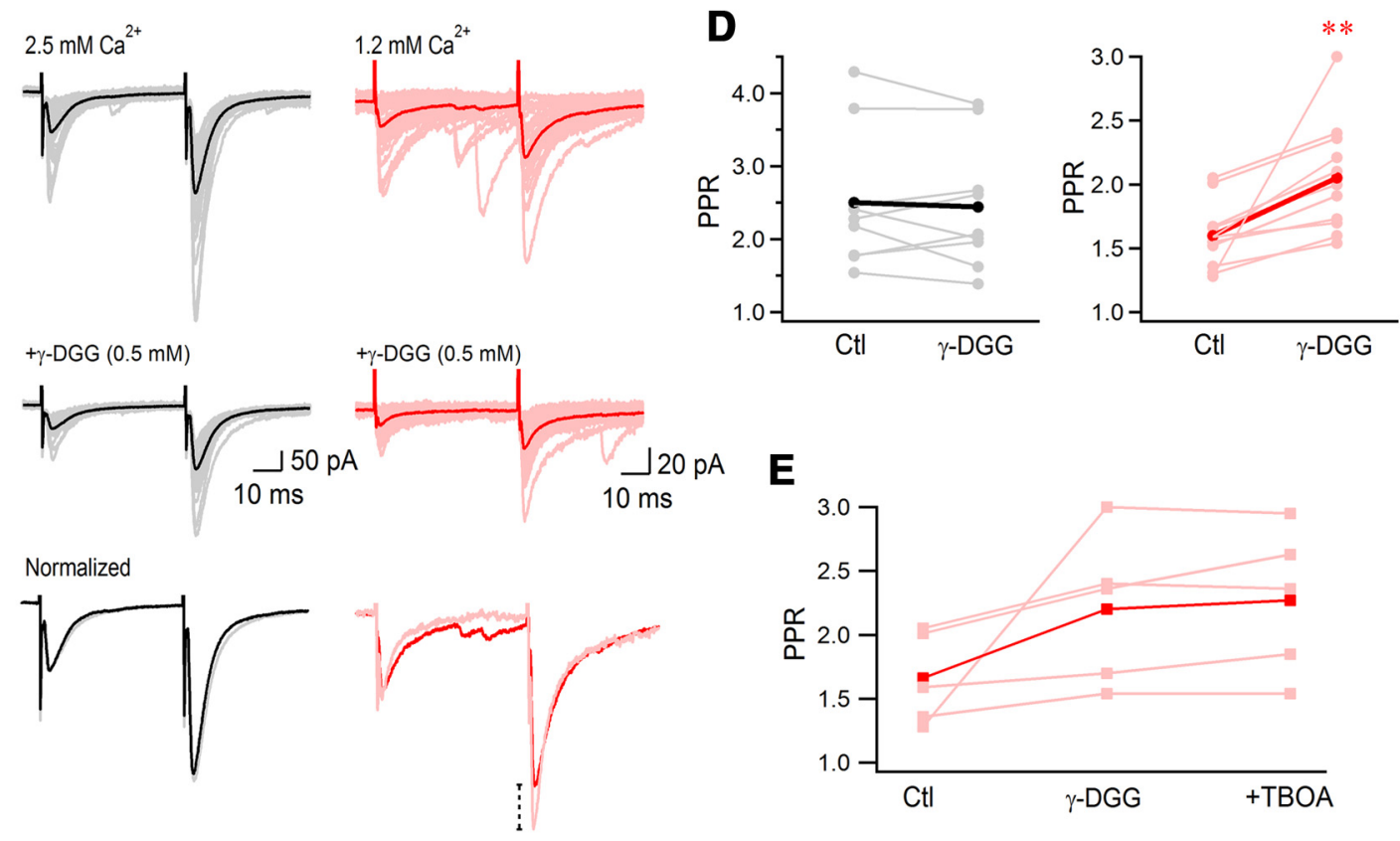

Figure 5. Increase in cleft glutamate concentration accompanies EPSC facilitation in condition of low release probability. $A$, Example traces of MF-evoked EPSCS recorded in controls and in the presence of $\gamma$-DGG $(0.5$ and $2 \mathrm{mM})$. B, Effects of $\gamma$-DGG $(0.5$ and $2 \mathrm{~mm})$ on EPSC amplitude and kinetics ( ${ }^{* *} p<0.01$, control vs $\gamma$-DGG). Amp., Amplitude. C, Example recordings of EPSCs evoked by paired-pulse stimulation $(50 \mathrm{~Hz})$ before and after application of $\gamma$-DGG $(0.5 \mathrm{~mm})$ in ACSF containing $1.2 \mathrm{~mm}$ (red) and $2.5 \mathrm{~mm}$ (black) $\mathrm{Ca}^{2+}$. Bottom, EPSC averages normalized to the first stimulus before (dark traces) and after (light traces) application of $\gamma$-DGG in both conditions. D, Summary graphs of $\gamma$-DGG effect on the PPR in $2.5 \mathrm{~mm}$ (black) and $1.2 \mathrm{~mm}$ (red) external Ca ${ }^{2+}\left({ }^{* *} p<0.01\right.$, control vs $\gamma$-DGG). $\boldsymbol{E}$, TBOA had no effect on the PPR after application of $\gamma$-DGG in $1.2 \mathrm{~mm}$ external $\mathrm{Ca}^{2+}$. Ctl, Control.

icles in the synaptic cleft in response to a single AP. Indeed, at several central synapses, including the calyx of Held and climbing fiber-Purkinje cell synapses (Wadiche and Jahr, 2001; Taschenberger et al., 2002), more than one vesicle can be released at a single release site by an AP (Tong and Jahr, 1994). At MF to CA3 pyramidal cells synapses, multivesicular release was suggested by means of release rate analysis (Hallermann et al., 2003). In line with this conclusion, our results support a gradual increase in $Q$ during trains of facilitating EPSCs. Accordingly, the synchronous release of additional vesicles at a single release site could explain the increase in $Q$ during the trains.

Thus, to investigate whether multivesicular release is the mechanism involved in short-term facilitation of EPSCs in 1.2 mM Ca ${ }^{2+}$, we used the low-affinity AMPAR antagonist $\gamma$-DGG. This compound blocks EPSCs mediated by lower cleft glutamate concentration more effectively than EPSCs evoked by higher cleft glutamate (Wadiche and Jahr, 2001). If during a paired-pulse stimulation paradigm the second facilitating EPSC is blocked to a lesser extent than the first, we could conclude that higher gluta- mate concentration is present in the synaptic cleft. Previously, we performed control experiments to validate the ability of the drug to partially block AMPARs and reduce EPSC amplitude in our conditions.

As expected, higher concentrations of $\gamma$-DGG blocked EPSCs to a greater extent (Fig. $5 A$ ) but did not significantly affect the kinetics of EPSCs (Fig. 5B). We then investigated the effect of $\gamma$-DGG on the PPR of facilitating EPSCs. In $2.5 \mathrm{~mm}$ external $\mathrm{Ca}^{2+}, 500 \mu \mathrm{M} \gamma$-DGG inhibited both EPSCs similarly (PPR control, $2.48 \pm 0.47$; PPR $\gamma$-DGG, $2.20 \pm 0.54 ; n=4 ; p=0.11)$. This effect was independent of the concentration of the low-affinity antagonist, because $2 \mathrm{~mm} \gamma$-DGG likewise had no effect on the PPR (PPR control, $2.52 \pm 0.46$; PPR $\gamma$-DGG, $2.63 \pm 0.34 ; n=5$; $p=0.46)$. Thus, these data were pooled. In contrast, in low external calcium, we observed that the first EPSC was significantly more inhibited by $\gamma$-DGG than the second (first EPSC, $57.7 \pm$ $6.1 \%$ inhibition; second EPSC, $46.7 \pm 7.2 \%$ inhibition; $n=11$; $p=0.0006$; Fig. 5), which was reflected by an increased PPR measured in $\gamma$-DGG (PPR control, $1.6 \pm 0.08$; PPR $\gamma$-DGG, 
$2.05 \pm 0.13 ; n=11 ; p=0.007)$. Furthermore, $500 \mu \mathrm{M} \gamma$-DGG had a significantly larger inhibitory effect on the first EPSC evoked in $1.2 \mathrm{mM} \mathrm{Ca}^{2+}$ than on the first EPSC evoked in $2.5 \mathrm{~mm}$ $\mathrm{Ca}^{2+}\left(1.2 \mathrm{mM} \mathrm{Ca}^{2+}, 57.7 \pm 6.1 \%\right.$ inhibition, $n=5 ; 2.5 \mathrm{~mm}$ $\mathrm{Ca}^{2+}, 37.2 \pm 2.9 \%$ inhibition, $n=11 ; p=0.01$; Fig. 5 ), possibly reflecting the larger initial $Q$ observed in $2.5 \mathrm{~mm} \mathrm{Ca}^{2+}$ (Fig. 4) and suggesting that multivesicular release is already fully operational for the first EPSC evoked in conditions of elevated calcium. Together, these data show that cleft glutamate concentration is increased for the second stimuli in $1.2 \mathrm{mM} \mathrm{Ca}^{2+}$ but not in 2.5 $\mathrm{mM} \mathrm{Ca}^{2+}$ and that cleft glutamate concentration for single stimulus is higher in conditions of elevated release probability.

The short distance between multiple release sites at MF-CA3 synapses (Rollenhagen et al., 2007) could confound interpretation of these results in low external calcium. Although unlikely because of the low release probability conditions, glutamate spillover between adjacent releases sites (Barbour and Häusser, 1997; Rusakov and Kullmann, 1998; Auger and Marty, 2000) could be responsible for the increase in cleft glutamate concentration observed (Satake et al., 2012). To rule out this possibility, we coapplied the glutamate transporter antagonist TBOA $(10 \mu \mathrm{M})$ after $\gamma$-DGG (Wadiche and Jahr, 2001). If the increase in PPR results from glutamate spillover between release sites, then TBOA should increase this effect and a larger PPR should be observed. In the five neurons investigated, the PPR was similarly increased by $\gamma$-DGG alone and by $\gamma$-DGG plus TBOA (control, $1.66 \pm 0.16$; $\gamma$-DGG, $2.2 \pm 0.26 ; \gamma$-DGG + TBOA, $2.27 \pm 0.26 ; n=5 ; p=$ 0.35 ; Fig. $5 E$ ). These results suggest that there is an increase in cleft glutamate concentration during trains in $1.2 \mathrm{mM} \mathrm{Ca}^{2+}$. Therefore, synchronization of multivesicular release is the mechanism that supports short-term facilitation of EPSCs in conditions of low release probability.

\section{Calcium stores contribute to synchronization of multivesicular release}

Next, we thought to address the mechanisms synchronizing multivesicular release during trains of stimuli. Initially, we decided to look whether calcium release from intracellular stores could be the trigger for the synchronized release of multiple vesicles, as is the case in other systems (Llano et al., 2000; Gordon and Bains, 2005). At MF-CA3 synapses, calcium stores contribute to the total presynaptic calcium influx (Scott and Rusakov, 2006; Scott et al., 2008; Shimizu et al., 2008) and to short-term facilitation in certain conditions (Carter et al., 2002; Lauri et al., 2003). To examine the role of presynaptic calcium stores at MF terminals, we recorded EPSCs in control conditions and in the presence of the SERCA pump inhibitor CPA $(30 \mu \mathrm{M})$ to block calcium uptake in calcium stores and render them ineffective. CPA application did not have a significant effect on the basic properties of EPSCs (success rate, amplitude, rise time, decay $\tau$, and CV) in either low $(n=13)$ or normal $(n=8)$ extracellular calcium (Fig. $6 A, B)$.

We then addressed whether CPA had any effect on short-term facilitation during trains of EPSCs. We observed no effect of CPA on EPSC amplitudes in trains of stimuli recorded in $2.5 \mathrm{mM} \mathrm{Ca}^{2+}$ (control: first EPSC, $176.9 \pm 54.4$ pA; fifth EPSC, $542.1 \pm 114.2$ pA; CPA: first EPSC, $161.9 \pm 51.3$ pA; fifth EPSC, $454.2 \pm 121.4$; $n=8 ; p=0.23$; Fig. $6 D 1)$. In contrast, CPA significantly decreased the amplitude of EPSCs in trains of stimuli in $1.2 \mathrm{~mm}$ $\mathrm{Ca}^{2+}$ (control: first EPSC, $54.9 \pm 10.8 \mathrm{pA}$; fifth EPSC, $239.9 \pm$ 41.4 pA; CPA: first EPSC, $39.6 \pm 7.1$ pA; fifth EPSC, $132.1 \pm 28.4$; $n=8 ; p=0.002$; Fig. $6 D 2)$. These results suggest that calcium stores play a key role in the regulation of multivesicular release at MF-CA3 synapses.
Our previous results suggest that multivesicular release is already fully working in conditions of elevated extracellular $\mathrm{Ca}^{2+}$. However, we noted no effect of CPA application on short-term facilitation in $2.5 \mathrm{~mm}$ extracellular $\mathrm{Ca}^{2+}$. To resolve this contradiction, we hypothesized that, in conditions of high extracellular $\mathrm{Ca}^{2+}$, the contribution of $\mathrm{Ca}^{2+}$ stores is likely to be irrelevant to the synchronization of multivesicular release, because the terminal is already overwhelmed by a high concentration of $\mathrm{Ca}^{2+}$. Although the release from calcium stores still occurs and does contribute to the total calcium elevations observed in large MF boutons in $2 \mathrm{~mm}$ extracellular $\mathrm{Ca}^{2+}$ (Scott and Rusakov, 2006, Scott et al., 2008), it no longer appears to be an essential factor in the synchronization of multivesicular release (Fig. 6). In addition, previous studies demonstrated the absence of effect when calcium stores were blocked in high release probability conditions (Carter et al., 2002; Lauri et al., 2003) but a strong effect in conditions of low release probability. Thus, the entry of a higher concentration of calcium in conditions of elevated release probability could be sufficient by itself to fully synchronize multivesicular release. If our hypothesis is correct, CPA should have an effect on short-term facilitation in conditions of $2.5 \mathrm{~mm}$ extracellular calcium in the presence of EGTA-AM, because the excessive calcium invading the terminal in high release probability conditions will be buffered. Indeed, our results showed that the combined application of EGTA-AM and CPA not only diminished the facilitation significantly more than EGTA-AM alone (Fig. 2E) but surprisingly completely abolished short-term facilitation at the MF-CA3 synapse (control: first EPSC, $177.7 \pm 33.9 \mathrm{pA}$; 10th EPSC, $720.9 \pm 117.2$ pA; EGTA-AM + CPA: first EPSC, $34.9 \pm$ $13.6 \mathrm{pA} ; 10$ th EPSC, $37.5 \pm 11.8 \mathrm{pA} ; n=5 ; p=0.0038$ for 10 th EPSC in control vs drugs; Fig. $6 E, F)$. Overall, these results suggest that the contribution of calcium stores in high release probability conditions is negligible to short-term facilitation. Additionally, in conditions in which additional release sites cannot be recruited and intracellular calcium is buffered (EGTA$\mathrm{AM})$, short-term facilitation is controlled by the activation of calcium stores and also by the accumulation of intracellular calcium at the release site. Indeed, the buffering provided by EGTA when calcium stores are blocked was sufficient to fully abolish short-term facilitation at MF-CA3 synapses.

\section{Intraterminal calcium hotspots support recruitment of additional release sites}

Our results showed that only a partial block of short-term facilitation mediated by an increase in $N$ was possible with application of the slow calcium chelator EGTA-AM, suggesting that this mechanism is supported by loose coupling between $\mathrm{Ca}^{2+}$ entry site and the site of exocytosis (Borst and Sakmann, 1996; Meinrenken et al., 2002; Vyleta and Jonas, 2014). A hallmark feature of MFs is the large number of adjacent release sites formed by a single bouton on its CA3 pyramidal cell target (18-45 active zones, separated by as few as $450 \mathrm{~nm}$; Rollenhagen et al., 2007). Additionally, a global buffering of calcium is observed in $\mathrm{MF}$ boutons after activity (Vyleta and Jonas, 2014). Therefore, we posited that loose coupling between $\mathrm{Ca}^{2+}$ channels and neighboring release sites could allow diffusion of calcium ions between neighboring sites of exocytosis to favor the recruitment of additional release sites by increasing global residual calcium or bound calcium buffer after an AP (Vyleta and Jonas, 2014).

If this hypothesis is valid, calcium microdomains of variable amplitudes evoked by a single AP should be observed inside large MF boutons. The existence of such heterogeneity in calcium microdomains was demonstrated in large squid axonal terminals 
A

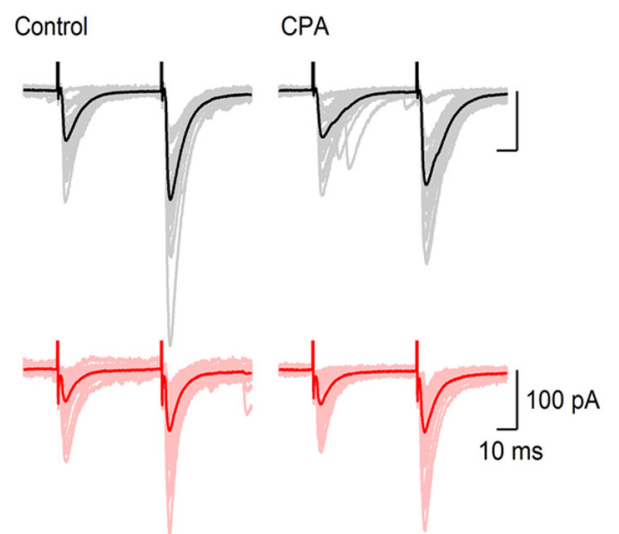

B

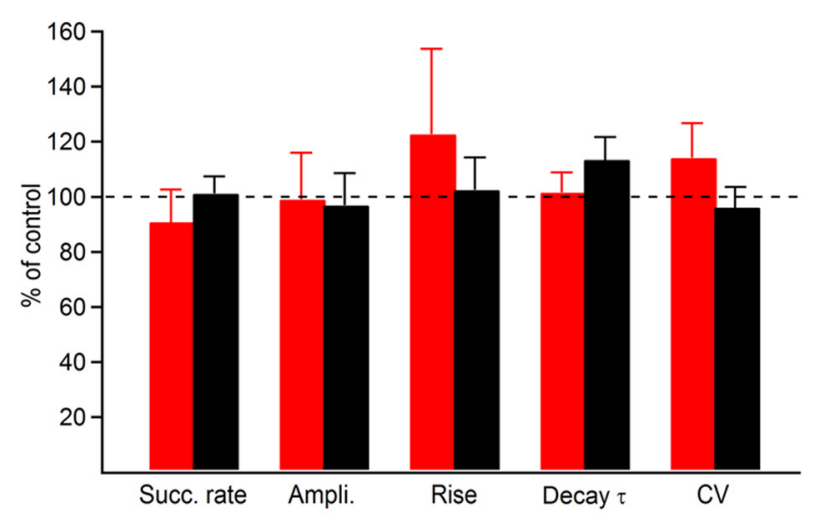

C

Control

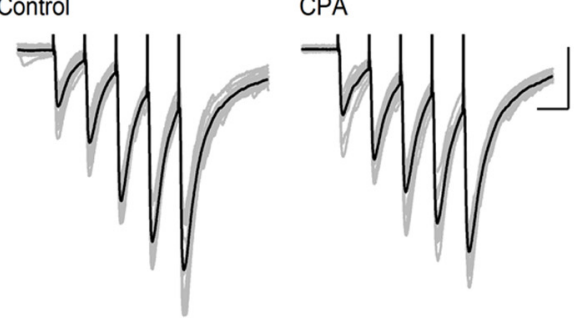

E

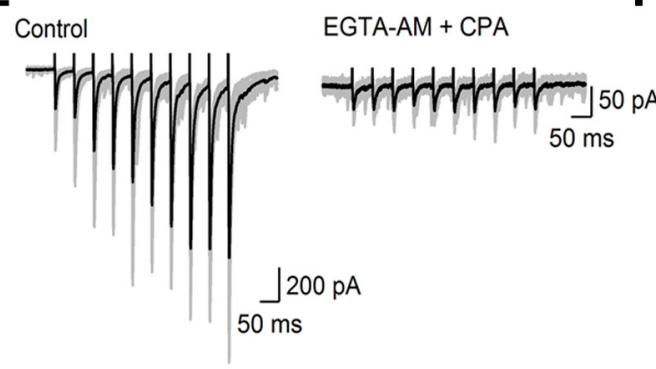

D1
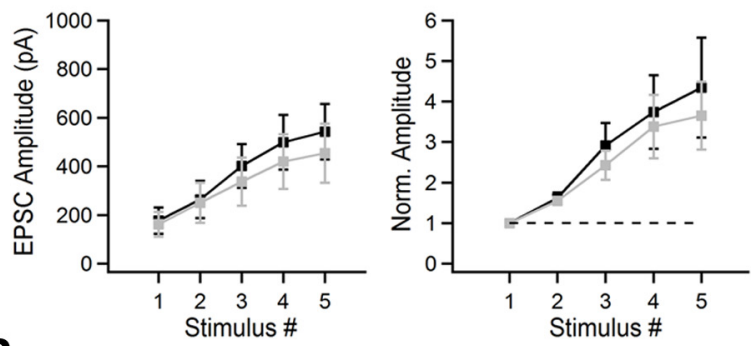

D2
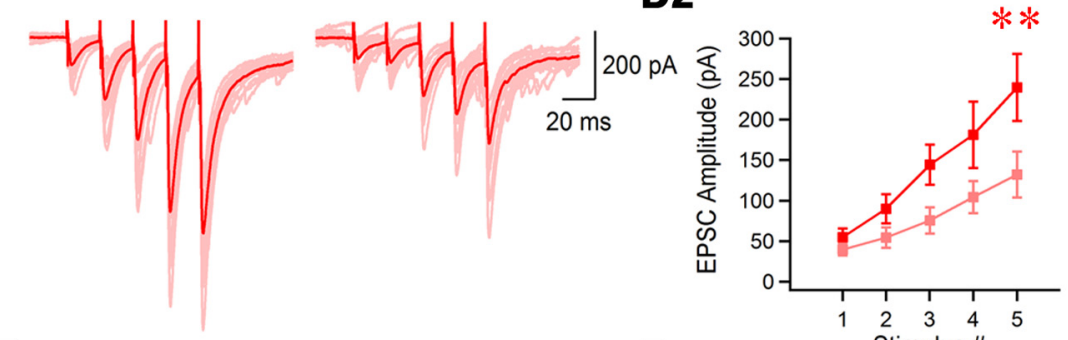

F

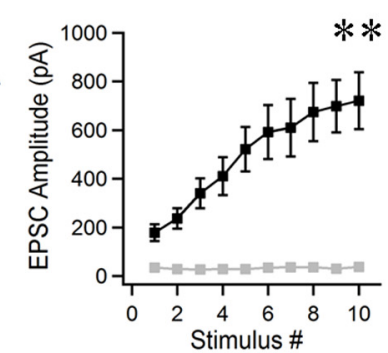

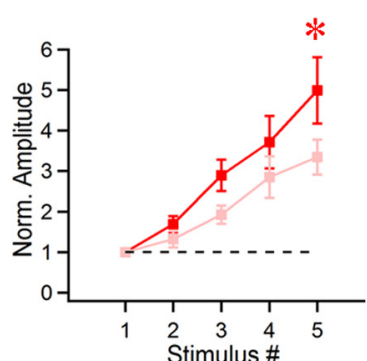

Stimulus \#

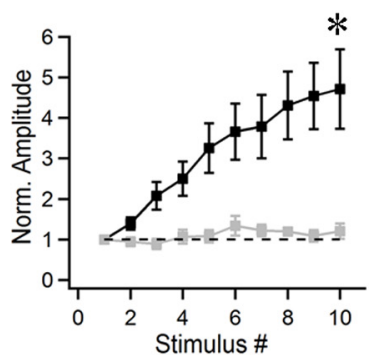

Figure 6. Intracellular calcium stores contribute to short-term facilitation in low extracellular $\mathrm{Ca}^{2+}$.A, Representative examples of EPSCs recorded in $2.5 \mathrm{~mm}$ (black) and $1.2 \mathrm{~mm}$ (red) external $\mathrm{Ca}^{2+}$ before and after application of CPA $(30 \mu \mathrm{M})$. B, Summary bar graph showing that addition of CPA had no significant effect on EPSC properties evoked by the first stimulus. Succ. rate, Success rate; Ampli, amplitude. C, Examples of EPSCs trains ( 5 stimuli at $50 \mathrm{~Hz}$ ) recorded in $2.5 \mathrm{~mm}$ (black) and $1.2 \mathrm{~mm}$ (red) external $\mathrm{Ca}^{2+}$ in controls and in the presence of CPA. D, Summary plots showing the absence of effect on EPSC amplitude of CPA during trains evoked in $2.5 \mathrm{~mm}$ external $\mathrm{Ca}^{2+}(\mathbf{D} 1)$ and the decrease in short-term facilitation of EPSCs induced by the application of CPA in low calcium conditions (D2; ${ }^{*} p<0.05$, 1st EPSC vs 5th EPSC; ${ }^{* *} p<0.01$, 1st EPSC vs 5th EPSC). E, Representative recording of EPSCs in control conditions and after the application of EGTA-AM (100 $\mu \mathrm{M}$ ) and CPA ( $30 \mu \mathrm{m} ; 10$ stimuli, $20 \mathrm{~Hz}$ ). $\boldsymbol{F}$, Summary plots showing the EPSC amplitude and the normalized EPSC amplitude as a function of stimulus number. Short-term facilitation was abolished after the application of EGTA-AM and (PA (gray trace; ${ }^{*} p<0.05$, 1st EPSC vs 10th EPSC; ${ }^{* *} p<0.01$, 1st EPSC vs 10 th EPSC).

(Llinás et al., 1992, 1995; Sugimori et al., 1994) but was not investigated in mammalian central synapses. We probed intraterminal calcium microdomains using a combination of randomaccess two-photon microscopy and electrophysiology. As a first step, we measured the point spread function (PSF) of the optical system using subresolution fluorescent beads to predict the volume of our measurements and to verify that single-point scan- ning sites could be recorded independently from each other. Because the PSF was determined to be $600 \mathrm{~nm}$ in the longest axis (Otsu et al., 2008), we chose to analyze intraterminal calcium elevations at locations separated by no less than this distance. The axial PSF was $\sim 1.2 \mu \mathrm{m}$, such that recordings obtained for single points are in fact volume-averaged measurements. To allow for uniform diffusion of a known dye concentration in the axonal structures and 
A

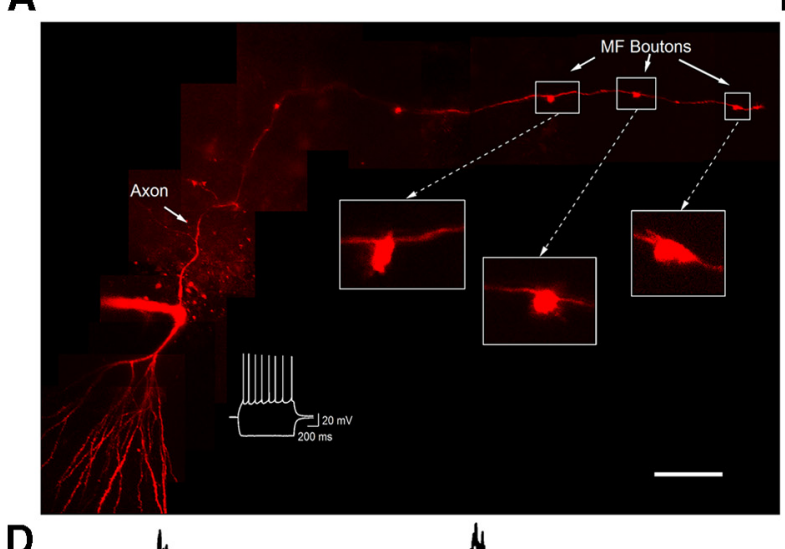

B

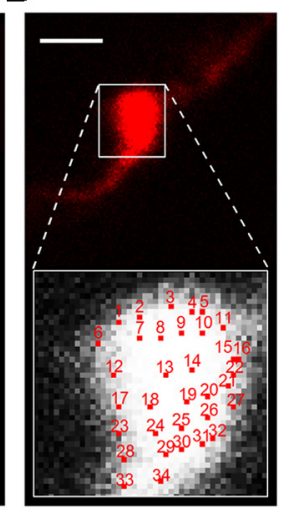

C

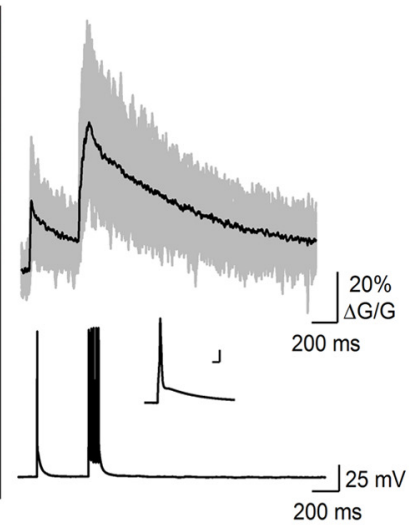

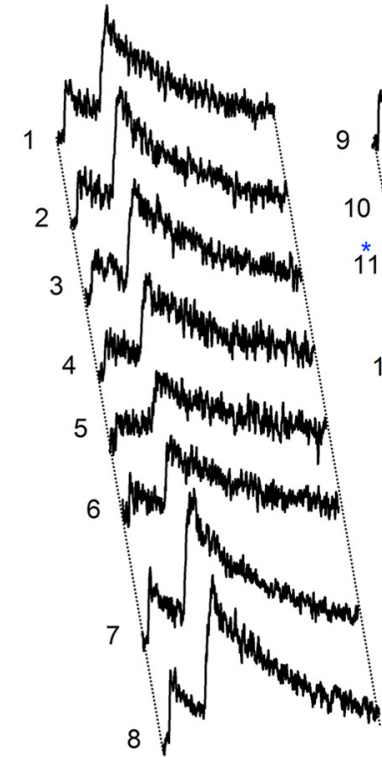
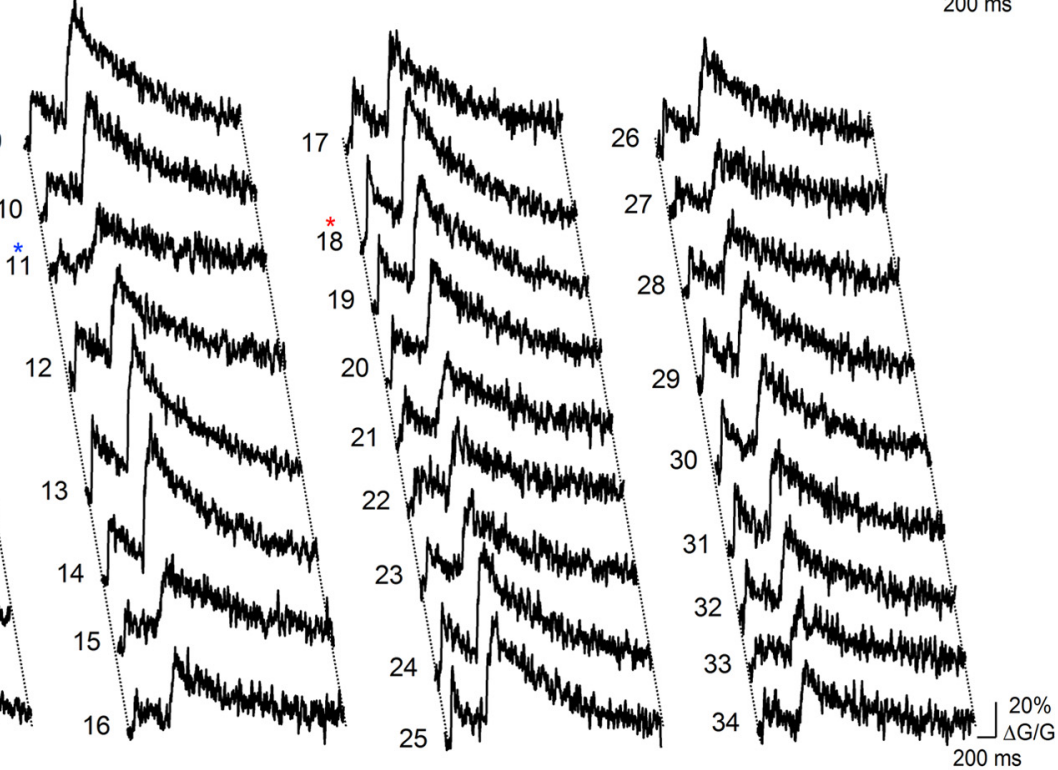

Figure 7. Calcium compartmentalization in a single MF terminal revealed by simultaneous multisite recordings of calcium elevations. A, Montage of severalZ-stack maximal projections obtained by two-photon microscopy of an Alexa Fluor-594-filled granule cell recorded in the whole-cell configuration. The long axonal projection forms large boutons (insets) contacting their pyramidal cell targets in the CA3 region. Hyperpolarization and depolarization of this granule cell showed a regularly spiking firing pattern typically observed in granule cells. Scale bar, $50 \mu \mathrm{m}$. $\boldsymbol{B}$, Single-plane image of a large MF bouton in CA3 filled with Alexa Fluor-594 by somatic whole-cell recording. Boxed region shows the expanded bouton with the location of points where the calcium elevations were recorded in that neuron. Scale bar, $5 \mu \mathrm{m}$. C, Calcium elevations recorded in the MF bouton shown in $\boldsymbol{B}$ in response to 1 and 5 APs evoked at the soma by current injection. Note the absence of failures in calcium elevations. Inset shows a single AP. $\boldsymbol{D}$, Calcium elevations recorded in the MF bouton shown in $\boldsymbol{B}$ according to their location. Traces shown are the average of four trials with $30 \mathrm{~s}$ intervals. Differences in calcium elevation amplitude in response to a single AP are clearly visible between the different points investigated [red asterisk indicates a trace (\#18) with large calcium influx, and blue asterisk indicates a trace (\#11) with weak calcium increase]. Note that, for closely placed points (\#15 and\#16), the calcium increase observed is nearly identical. Such double sampling of regions corresponding to the same PSF were excluded from additional analysis, but it demonstrates the precision of the imaging method.

to unambiguously identify the presynaptic terminals, we performed whole-cell patch-clamp recordings from single granule cells (Yasuda et al., 2004). Recordings were started $1 \mathrm{~h}$ after the whole-cell configuration was obtained to allow for equilibration of the dyes; for cells with an intact axon, its projection was traced to CA3 ( $n=8$ neurons of 21 granule cells attempted; Fig. 7A).

Given the large size of MF boutons (area in the imaged plane, $12.51 \pm 1.45 \mu \mathrm{m}^{2} ; n=8$ boutons; Fig. $8 B$ ) and a PSF of area 0.28 $\mu \mathrm{m}^{2}, 30-50$ calcium microdomains could be recorded independently and simultaneously in response to single APs. Care was taken not to analyze points separated by a distance inferior to the PSF (Fig. 7B), although adjacent points were sometimes recorded and used as a control. Similar to previous results (Scott and Rusakov, 2006), calcium elevations in MF boutons evoked by single APs were highly robust and never failed ( $n=8$ boutons; Fig. $7 C$ ). The calcium elevations recorded at various points in the MF boutons showed a high degree of variability (Fig. $7 D$ ), suggesting a varying influx of calcium in the different regions of the terminals.
Because the $z$-axis profile of the boutons could vary in the imaged plane, we obtained volume-independent measurements of calcium transients by normalizing the increase in calcium indicator with the fluorescence measurement of the morphological dye Alexa Fluor594 (Hildebrand et al., 2009; Fig. 8A). Therefore, calcium transients were normalized using the $\Delta G / R$ ratio to account for possible nonhomogeneities in bouton morphological structures. After this normalization process, calcium elevations remained highly variable at different points. To quantify the heterogeneity of calcium elevations across different locations in the boutons, we measured the SEM across points during recordings. Plotting the SE of $\Delta G / R$ in time revealed a significant increase in $\mathrm{SE}$ in response to $1 \mathrm{AP}$, suggesting that calcium elevation was non-uniform in the bouton (Fig. $8 D$ ). Furthermore, the peak SE observed for a single AP was similar to the peak error observed for five APs (Fig. 8A). Although this could be interpreted as activity-dependent standardization of the calcium elevation across the bouton, it is more likely to reflect the saturation of OGB-1 in the presence of higher intracellular calcium. Therefore, 
A1

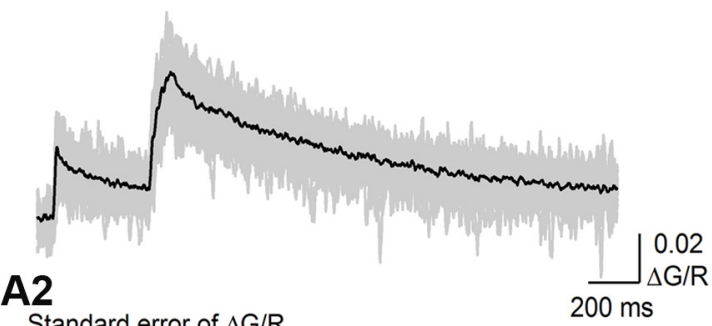

Standard error of $\Delta G / R$

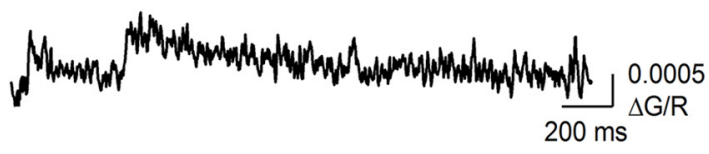

B
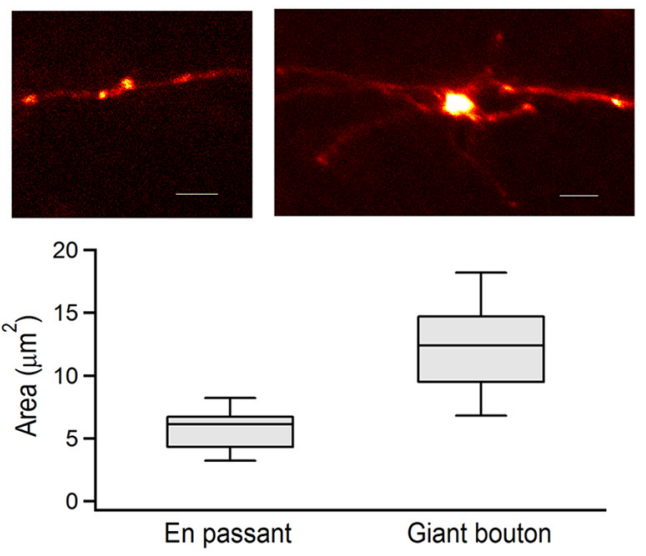

D

C1

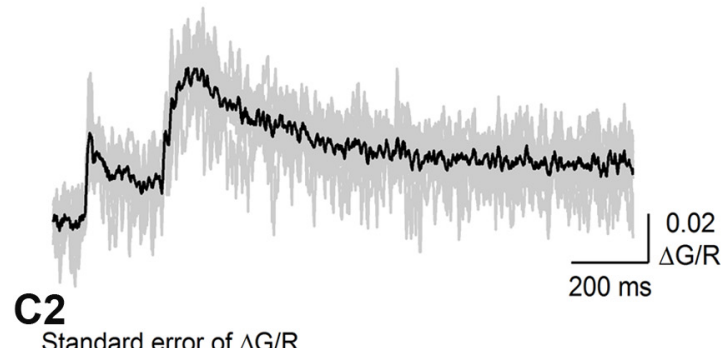

Standard error of $\Delta G / R$

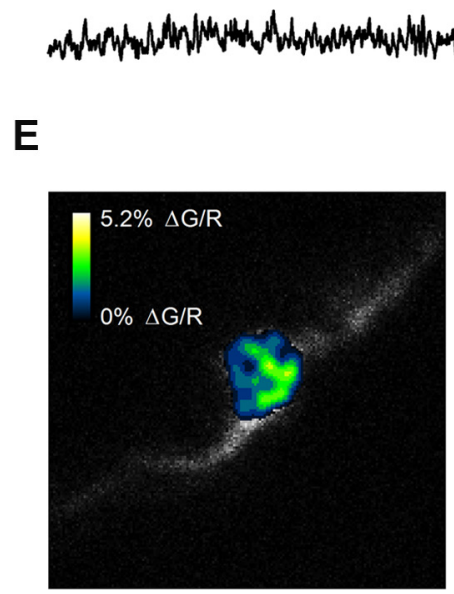

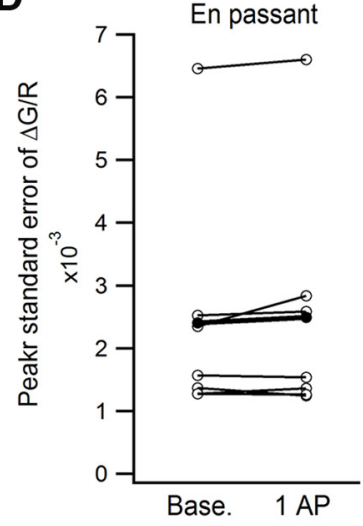

Giant bouton

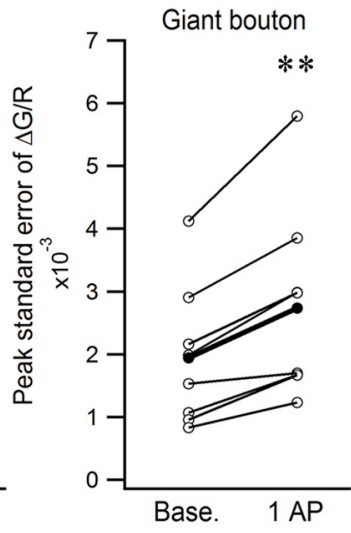
F 0.002 $200 \mathrm{~ms} \Delta \mathrm{G} / \mathrm{R}$

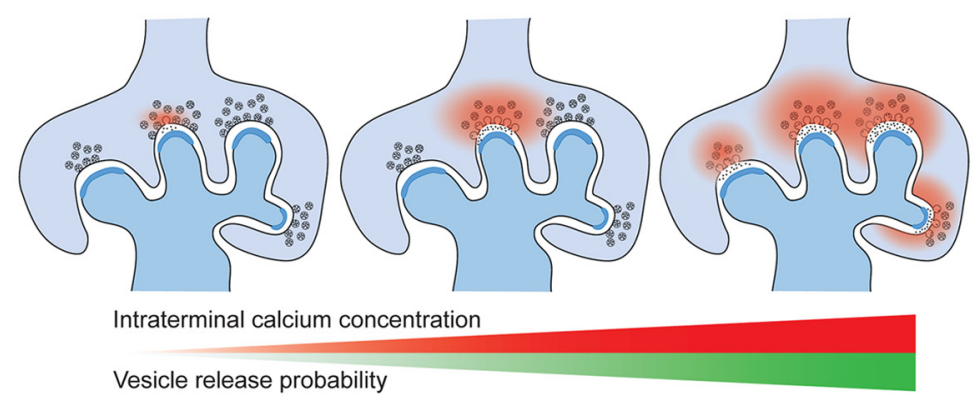

Figure 8. Compartmentalized calcium elevations in large MF boutons but not in en passant terminals. A1, Calcium transients (32 traces, with overlaid average) obtained by normalizing the change in calcium-sensitive green fluorescence to the red morphological dye. $\boldsymbol{A} 2$, The SE of the traces shown in $\boldsymbol{A} \mathbf{1}$ was used as a measure of the variation from the mean. Elevations in SE correspond to the timing of the single AP, and the 5 APs burst and show non-uniform calcium signals across points in the bouton. $\boldsymbol{B}$, Examples of two types of synaptic terminals found on the axons of granule cells. Morphological comparison between large MF boutons and small en passant terminals show the larger single-plane area in MF boutons. Scale bars, $5 \mu \mathrm{m}$. C1, Calcium elevations (14 traces, with overlaid average) obtained in an en passant terminal. Calculation of the SE between recorded points shows no increase in the deviation from the mean (C2) unlike in giant MF boutons (A1). $\boldsymbol{D}$, Quantification of the increase in SE by comparing the peak SE observed during the baseline (Base.) to the peak of the SE measured during one AP $\left({ }^{* *} p<0.01\right.$, baseline vs 1 AP). $\boldsymbol{E}$, Heat map of calcium elevations observed in the bouton shown in Figure 7 obtained by convoluting color-coded pixels according to calcium elevation amplitude. Color scale shows that warmer colors are associated with a larger $\Delta G / R$ ratio. Scale bar, $5 \mu \mathrm{m}$. $\boldsymbol{F}$, Summary diagram depicting how compartmentalized intraterminal calcium contributes to short-term facilitation at MF-CA3 synapses, with the synchronized release of additional vesicles at a single release site followed by the recruitment of additional release sites.

our results show that the calcium elevations in large MFs are heterogeneous and compartmentalized.

Compartmentalization of calcium microdomains is restricted to large MF terminals in granule cell axons

Based on anatomical properties, boutons could be separated in two groups: (1) large MF boutons with filopodial extensions; and
(2) small terminals protruding on the axon corresponding to en passant boutons (Fig. 8B). In line with the morphological characteristics of these terminals, the area of the structures in the imaged plane was significantly larger for the MF boutons than for the small en passant boutons (MF boutons, $12.5 \pm 1.45 \mu \mathrm{m}^{2}, n=$ 8; en passant boutons, $5.74 \pm 0.77 \mu \mathrm{m}^{2}, n=7, p=0.0017$; Fig. $8 A$ ). However, the amplitude of calcium elevations generated by 
one $\mathrm{AP}$ in these two groups was identical (MF boutons, $0.0240 \pm$ 0.0043 ; en passant boutons, $0.0233 \pm 0.0028, \Delta G / R ; n=7 ; p=$ 0.88 ). Although a large variation was observed in bouton size within the MF bouton population, no significant correlation could be found between the area in the imaged plane and the amplitude of the calcium transients ( $p=0.41$, Pearson's rank correlation). Finally, we thought to investigate whether heterogeneous intraterminal calcium elevations are a feature of large MF terminals or whether they can also be found in small en passant boutons. Variance between points recorded in en passant boutons was measured similarly to MF boutons (Fig. $8 C$ ). In contrast to large MF boutons, no calcium hotspots in response to an AP could be observed in small en passant terminals, as revealed by the uniform calcium transients recorded and the measured SE of $\Delta G / R$ (MF boutons, $143.8 \pm 6.5 \%$ of baseline, $n=8, p=0.0017$; en passant boutons, $103 \pm 2.7 \% n=7, p=$ 0.29; Fig. $8 D$ ).

To better illustrate the non-uniform calcium elevations recorded in single MF boutons, we superimposed the measured values of peak calcium transients $(\Delta G / R)$ on their corresponding position in the bouton and color coded the pixels as a function of calcium transient amplitude (Fig. 8E). A 3D Gaussian blur was applied to the image, with a radius corresponding to the measured PSF. Although limited by various factors, including the size of the PSF, the properties of the calcium indicator, and the convolution itself, the topographical calcium map generated illustrates the highly heterogeneous calcium microdomains present in large MF terminals (Fig. 8E).

\section{Discussion}

Short-term facilitation of MF inputs to CA3 pyramidal cells is a key feature of this synapse. Our data describe the mechanisms that are responsible for this fast and robust increase in glutamate release during high-frequency granule cell firing. We found that the switch from univesicular to multivesicular release and the recruitment of additional release sites supports facilitation as the probability of release increases with the number of stimuli. We also found that calcium elevation in MF terminals is nonuniform, leading to the development of distinct presynaptic calcium microdomains.

Increasing the number of vesicles that are released in response to a single stimulus can be a very effective way to increase or decrease synaptic efficacy. Multivesicular release has been shown to contribute to both short- and long-term forms of synaptic plasticity (Reid et al., 2004; Bender et al., 2009; Kuzmiski et al., 2010; Quinlan and Hirasawa, 2013). Changes in the prevalence in multivesicular release can be bidirectional, leading to synaptic depression in which LTD is expressed presynaptically (Lei and McBain, 2004; Qiu and Knöpfel, 2009). Neuromodulators can also influence this presynaptic mechanism, leading to transient changes in glutamatergic transmission (Gordon and Bains, 2005). Our data show that the switch from univesicular to multivesicular release at MF terminals only can be observed at lower $(1.2 \mathrm{mM}) \mathrm{Ca}^{2+}$ concentrations; this value is compatible with the estimated concentration of extracellular $\mathrm{Ca}^{2+}$ in in vivo conditions (Jones and Keep, 1988; Chauvette et al., 2012), suggesting that an alteration in the number of vesicles released during AP firing can be a key element of short-term changes in synaptic strength. However, at higher extracellular calcium concentrations or in later segments of longer trains, multivesicular release was already operational and did not contribute to additional increases in glutamate release. Under this condition, we found that the number of functional release sites could explain the constant and robust increase of postsynaptic responses. According to our results, the consistently larger PPR recorded in $2.5 \mathrm{~mm}$ extracellular $\mathrm{Ca}^{2+}$ could indicate that the recruitment of additional release sites increases the EPSC amplitude more than synchronization of multivesicular release. The increase in the number of release sites traditionally was attributed to long-term changes in synaptic connectivity patterns (Faber and Korn, 1991) or to the unveiling of silent synapses (Reid et al., 2004; Kerchner and Nicoll, 2008). Our findings are compatible with the scenario in which the increase in $N$ is the result of increase in $p$ among individual release sites operating with very different initial release probability. When $p$ is low, only a subpopulation of release sites would be functional, but as $p$ increases, even release sites with very low initial release probability would contribute to the release of glutamate. Although it is difficult to know whether the recruitment of additional release sites is the result of calcium buildup or the activation of supplementary calcium channels at more depolarized potential, highly compartmentalized calcium domains in the terminal could explain heterogeneity of release probability among individual release sites.

\section{Calcium dynamics gates MF-CA3 short-term facilitation}

A gradual increase in presynaptic calcium concentration controls short-term facilitation during repetitive activity at MF-CA3 synapses (Regehr et al., 1994; Scott and Rusakov, 2006). How is this summation achieved? Propagation of APs to MF boutons triggers the opening of P/Q-, N-, and R-type voltage-gated calcium channels (VGCCs) (Castillo et al., 1996; Breustedt et al., 2003; Pelkey et al., 2006), with P/Q-type VGCCs contributing the major fraction of intrabouton calcium elevations (Pelkey et al., 2006; Li et al., 2007). Activity-dependent broadening of APs will increase the total presynaptic calcium through the recruitment of additional VGCCs and their prolonged opening (Geiger and Jonas, 2000). Once calcium invades the terminal, the concentration can be further elevated by activation of calcium stores but will be rapidly buffered by endogenous calcium binding proteins. Both mechanisms support short-term facilitation at MF-CA3 synapses (Geiger and Jonas, 2000; Lauri et al., 2003; Vyleta and Jonas, 2014).

Intracellular calcium stores are expressed in MF boutons (Petukhov and Popov, 1986; Padua et al., 1991) and contribute up to $20 \%$ to AP-evoked calcium elevations in MF terminals (Liang et al., 2002; Scott and Rusakov, 2006; Scott et al., 2008; Shimizu et al., 2008). Interestingly, Lauri et al. (2003) showed the importance of calcium stores for short-term facilitation of EPSCs in conditions of $2 \mathrm{~mm}$ extracellular calcium but that calcium stores do not contribute to short-term facilitation in $4 \mathrm{~mm}$ calcium (Carter et al., 2002). However, these experiments were done at room temperature. Given that all our experiments were performed at near physiological temperature and that presynaptic calcium entry and calcium buffering are highly temperaturedependent processes (Beierlein et al., 2004; Nouvian, 2007), our results agree with these findings. Thus, in low release probability conditions, intracellular calcium stores will boost calcium inside the terminal and produce increased glutamate release.

It was demonstrated recently that global instead of local calcium buffer saturation in MF boutons contributes to short-term facilitation (Vyleta and Jonas, 2014). Our results are in strong agreement with this finding, in addition to demonstrating the increase in the number of release sites recruited during shortterm facilitation. As the intensity of activity increases, release sites that were at first inactive can sense the general increase in activity through the globalized saturated calcium buffers. As such, an initially low increase in intraterminal calcium will cause a larger 
increase in free calcium when the calcium buffers are already bound. Hence, a release site with a weak initial $p$ will have increased chances of being solicited by calcium during bursts of activity.

\section{Compartmentalized calcium elevations in MF boutons}

To our knowledge, this is the first study that demonstrates compartmentalized calcium elevations in a single presynaptic terminal in the mammalian CNS (Llinás et al., 1992; Rusakov, 2006; Vyleta and Jonas, 2014). By using random-access two-photon microscopy, we probed presynaptic calcium elevations in multiple regions with a high temporal resolution in large MF boutons (Salomé et al., 2006; Otsu et al., 2008).

It is important to consider the main technical limitation of our approach for data interpretation. Given the axial PSF of $1.2 \mu \mathrm{m}$ measured in the RAMP system, we are measuring calcium elevation averaged across the whole depth of the bouton. Although our measurements are adjusted for nonhomogeneities in bouton morphology by using the $\Delta G / R$ ratio instead of $\Delta G / G$ (Hildebrand et al., 2009), this normalization will not account for multiple calcium hotspots located along the same depth. Therefore, it would be impossible to distinguish their spatial origins and to conclude on the precise number of active regions based on these measurements. However, even considering these limitations, our results show that MF terminals possess local calcium microdomains. Given that the release machinery is concentrated at active zones, it would be tempting to hypothesize that sites with heightened calcium elevations for one AP correspond to more active release sites (Fedchyshyn and Wang, 2005).

The peculiar MF boutons form 15-45 release sites separated by as few as $450 \mathrm{~nm}$ on their CA3 pyramidal cell targets (Rollenhagen et al., 2007). The calyx of Held forms 500-700 active zones on their target (Sätzler et al., 2002; Taschenberger et al., 2002) but with a distance between active zones similar to that observed at MFs (590 nm; Sätzler et al., 2002). Do these two synapses possess similar compartmentalized calcium dynamics? Spirou et al. (2008) showed by using modeling approaches that calcium elevations can be heterogeneous in calyx of Held terminals. Nonuniform calcium elevations are predicted to occur via variable positioning of $\mathrm{Na}^{+}$and $\mathrm{K}^{+}$channels in the terminal (Spirou et al., 2008). Although a high concentration of $\mathrm{Na}^{+}$channels are found in the MF terminals (Engel and Jonas, 2005), it is yet unknown whether they are distributed in a non-uniform manner that could support heterogeneous calcium increases.

Why do calcium microdomains need to be segregated in MF terminals but then generalized to the whole structure through calcium buffering (our results and (Vyleta and Jonas, 2014)? Giant MF boutons are several-fold larger than most small presynaptic terminals in the CNS (Rollenhagen et al., 2007). For example, in the same region of the hippocampus, CA3 pyramidal cells form small boutons on their synaptic targets (Holderith et al., 2012). Small boutons of CA3 pyramidal cells exhibit terminalspecific calcium elevations, and some boutons originating from the same cell experience larger calcium influx than others for a given AP (Holderith et al., 2012). Accordingly, because calcium hotspots are observed in MF boutons, the different release sites at MF terminals could be first considered as an independent mediator of neurotransmission when the granule cell is weakly active. However, as the level of activity increases, previously inactive release sites sense globalized activity in the bouton and contribute to discharge larger amounts of glutamate. Thus, cooperative action of the different release sites in higher regimens of activity could ensure that MF terminals can fulfill their role as conditional detonator synapses.

\section{Notes}

Supplemental material for this article is available at http://katalintoth. $\mathrm{ca} / \mathrm{LAB}-\mathrm{PAGE} / \mathrm{Cartoon}$.html. Video/diagram summary of findings presented in this manuscript. This material has not been peer reviewed.

\section{References}

Acsády L, Kamondi A, Sík A, Freund T, Buzsáki G (1998) GABAergic cells are the major postsynaptic targets of mossy fibers in the rat hippocampus. J Neurosci 18:3386-3403. Medline

Amaral DG, Dent JA (1981) Development of the mossy fibers of the dentate gyrus: I. A light and electron microscopic study of the mossy fibers and their expansions. J Comp Neurol 195:51-86. CrossRef Medline

Atluri PP, Regehr WG (1996) Determinants of the time course of facilitation at the granule cell to Purkinje cell synapse. J Neurosci 16:5661-5671. Medline

Auger C, Marty A (2000) Quantal currents at single-site central synapses. J Physiol 526:3-11. CrossRef Medline

Auger C, Kondo S, Marty A (1998) Multivesicular release at single functional synaptic sites in cerebellar stellate and basket cells. J Neurosci 18: 4532-4547. Medline

Barbour B, Häusser M (1997) Intersynaptic diffusion of neurotransmitter. Trends Neurosci 20:377-384. CrossRef Medline

Beierlein M, Gee KR, Martin VV, Regehr WG (2004) Presynaptic calcium measurements at physiological temperatures using a new class of dextranconjugated indicators. J Neurophysiol 92:591-599. CrossRef Medline

Bender VA, Pugh JR, Jahr CE (2009) Presynaptically expressed long-term potentiation increases multivesicular release at parallel fiber synapses. J Neurosci 29:10974-10978. CrossRef Medline

Bischofberger J, Engel D, Li L, Geiger JR, Jonas P (2006) Patch-clamp recording from mossy fiber terminals in hippocampal slices. Nat Protoc 1:2075-2081. CrossRef Medline

Blatow M, Caputi A, Burnashev N, Monyer H, Rozov A (2003) Ca2+ buffer saturation underlies paired pulse facilitation in calbindin-D28kcontaining terminals. Neuron 38:79-88. CrossRef Medline

Borst JG, Sakmann B (1996) Calcium influx and transmitter release in a fast CNS synapse. Nature 383:431-434. CrossRef Medline

Breustedt J, Vogt KE, Miller RJ, Nicoll RA, Schmitz D (2003) Alpha1Econtaining $\mathrm{Ca} 2+$ channels are involved in synaptic plasticity. Proc Natl Acad Sci U S A 100:12450-12455. CrossRef Medline

Bucurenciu I, Kulik A, Schwaller B, Frotscher M, Jonas P (2008) Nanodomain coupling between $\mathrm{Ca} 2+$ channels and $\mathrm{Ca} 2+$ sensors promotes fast and efficient transmitter release at a cortical GABAergic synapse. Neuron 57:536-545. CrossRef Medline

Burnashev N, Rozov A (2005) Presynaptic Ca2+ dynamics, Ca2+ buffers and synaptic efficacy. Cell Calcium 37:489-495. CrossRef Medline

Callaway EM, Katz LC (1993) Photostimulation using caged glutamate reveals functional circuitry in living brain slices. Proc Natl Acad Sci U S A 90:7661-7665. CrossRef Medline

Carter AG, Vogt KE, Foster KA, Regehr WG (2002) Assessing the role of calcium-induced calcium release in short-term presynaptic plasticity at excitatory central synapses. J Neurosci 22:21-28. Medline

Castillo PE, Salin PA, Weisskopf MG, Nicoll RA (1996) Characterizing the site and mode of action of dynorphin at hippocampal mossy fiber synapses in the guinea pig. J Neurosci 16:5942-5950. Medline

Chauvette S, Seigneur J, Timofeev I (2012) Sleep oscillations in the thalamocortical system induce long-term neuronal plasticity. Neuron 75:11051113. CrossRef Medline

Chicurel ME, Harris KM (1992) Three-dimensional analysis of the structure and composition of CA3 branched dendritic spines and their synaptic relationships with mossy fiber boutons in the rat hippocampus. J Comp Neurol 325:169-182. CrossRef Medline

Christie JM, Jahr CE (2006) Multivesicular release at Schaffer collateralCA1 hippocampal synapses. J Neurosci 26:210-216. CrossRef Medline

Clements JD, Silver RA (2000) Unveiling synaptic plasticity: a new graphical and analytical approach. Trends Neurosci 23:105-113. CrossRef Medline

Contractor A, Swanson G, Heinemann SF (2001) Kainate receptors are involved in short- and long-term plasticity at mossy fiber synapses in the hippocampus. Neuron 29:209-216. CrossRef Medline

Csicsvari J, Jamieson B, Wise KD, Buzsáki G (2003) Mechanisms of gamma 
oscillations in the hippocampus of the behaving rat. Neuron 37:311-322. CrossRef Medline

Denk W, Strickler JH, Webb WW (1990) Two-photon laser scanning fluorescence microscopy. Science 248:73-76. CrossRef Medline

Eggermann E, Bucurenciu I, Goswami SP, Jonas P (2012) Nanodomain coupling between $\mathrm{Ca}^{2+}$ channels and sensors of exocytosis at fast mammalian synapses. Nat Rev Neurosci 13:7-21. CrossRef Medline

Engel D, Jonas P (2005) Presynaptic action potential amplification by voltage-gated $\mathrm{Na}+$ channels in hippocampal mossy fiber boutons. Neuron 45:405-417. CrossRef Medline

Faber DS, Korn H (1991) Applicability of the coefficient of variation method for analyzing synaptic plasticity. Biophys J 60:1288-1294. CrossRef Medline

Fedchyshyn MJ, Wang LY (2005) Developmental transformation of the release modality at the calyx of Held synapse. J Neurosci 25:4131-4140. CrossRef Medline

Foster KA, Crowley JJ, Regehr WG (2005) The influence of multivesicular release and postsynaptic receptor saturation on transmission at granule cell to Purkinje cell synapses. J Neurosci 25:11655-11665. CrossRef Medline

Geiger JR, Jonas P (2000) Dynamic control of presynaptic $\mathrm{Ca}^{2+}$ inflow by fast-inactivating $\mathrm{K}^{+}$channels in hippocampal mossy fiber boutons. Neuron 28:927-939. CrossRef Medline

Goldberg JH, Yuste R (2004) A practical guide: two-photon calcium imaging of spines and dendrites. In: Imaging in neuroscience and development (Yuste R, Konnerth A, eds.). Cold Spring Harbor, NY: Cold Spring Harbor Laboratory.

Gordon GR, Bains JS (2005) Noradrenaline triggers multivesicular release at glutamatergic synapses in the hypothalamus. J Neurosci 25:1138511395. CrossRef Medline

Hallermann S, Pawlu C, Jonas P, Heckmann M (2003) A large pool of releasable vesicles in a cortical glutamatergic synapse. Proc Natl Acad Sci U S A 100:8975-8980. CrossRef Medline

Hefft S, Jonas P (2005) Asynchronous GABA release generates long-lasting inhibition at a hippocampal interneuron-principal neuron synapse. Nat Neurosci 8:1319-1328. CrossRef Medline

Henze DA, Wittner L, Buzsáki G (2002) Single granule cells reliably discharge targets in the hippocampal CA3 network in vivo. Nat Neurosci 5:790-795. CrossRef Medline

Hildebrand ME, Isope P, Miyazaki T, Nakaya T, Garcia E, Feltz A, Schneider T, Hescheler J, Kano M, Sakimura K, Watanabe M, Dieudonné S, Snutch TP (2009) Functional coupling between mGluR1 and Cav3.1 T-type calcium channels contributes to parallel fiber-induced fast calcium signaling within Purkinje cell dendritic spines. J Neurosci 29:9668-9682. CrossRef Medline

Holderith N, Lorincz A, Katona G, Rózsa B, Kulik A, Watanabe M, Nusser Z (2012) Release probability of hippocampal glutamatergic terminals scales with the size of the active zone. Nat Neurosci 15:988-997. CrossRef Medline

Jonas P, Major G, Sakmann B (1993) Quantal components of unitary EPSCs at the mossy fibre synapse on CA3 pyramidal cells of rat hippocampus. J Physiol 472:615-663. Medline

Jones HC, Keep RF (1988) Brain fluid calcium concentration and response to acute hypercalcaemia during development in the rat. J Physiol 402: 579-593. Medline

Jung MW, McNaughton BL (1993) Spatial selectivity of unit activity in the hippocampal granular layer. Hippocampus 3:165-182. CrossRef Medline

Kerchner GA, Nicoll RA (2008) Silent synapses and the emergence of a postsynaptic mechanism for LTP. Nat Rev Neurosci 9:813-825. CrossRef Medline

Klausnitzer J, Manahan-Vaughan D (2008) Frequency facilitation at mossy fiber-CA3 synapses of freely behaving rats is regulated by adenosine A1 receptors. J Neurosci 28:4836-4840. CrossRef Medline

Kuzmiski JB, Marty V, Baimoukhametova DV, Bains JS (2010) Stressinduced priming of glutamate synapses unmasks associative short-term plasticity. Nat Neurosci 13:1257-1264. CrossRef Medline

Kwon HB, Castillo PE (2008) Role of glutamate autoreceptors at hippocampal mossy fiber synapses. Neuron 60:1082-1094. CrossRef Medline

Lauri SE, Bortolotto ZA, Nistico R, Bleakman D, Ornstein PL, Lodge D, Isaac JT, Collingridge GL (2003) A role for Ca2+ stores in kainate receptordependent synaptic facilitation and LTP at mossy fiber synapses in the hippocampus. Neuron 39:327-341. CrossRef Medline
Lawrence JJ, Grinspan ZM, McBain CJ (2004) Quantal transmission at mossy fibre targets in the CA3 region of the rat hippocampus. J Physiol 554:175-193. CrossRef Medline

Lei S, McBain CJ (2004) Two Loci of expression for long-term depression at hippocampal mossy fiber-interneuron synapses. J Neurosci 24:21122121. CrossRef Medline

Li L, Bischofberger J, Jonas P (2007) Differential gating and recruitment of $\mathrm{P} / \mathrm{Q}-, \mathrm{N}-$, and R-type Ca2+ channels in hippocampal mossy fiber boutons. J Neurosci 27:13420-13429. CrossRef Medline

Liang Y, Yuan LL, Johnston D, Gray R (2002) Calcium signaling at single mossy fiber presynaptic terminals in the rat hippocampus. J Neurophysiol 87:1132-1137. Medline

Llano I, González J, Caputo C, Lai FA, Blayney LM, Tan YP, Marty A (2000) Presynaptic calcium stores underlie large-amplitude miniature IPSCs and spontaneous calcium transients. Nat Neurosci 3:1256-1265. CrossRef Medline

Llinás R, Sugimori M, Silver RB (1992) Microdomains of high calcium concentration in a presynaptic terminal. Science 256:677-679. CrossRef Medline

Llinás R, Sugimori M, Silver RB (1995) Time resolved calcium microdomains and synaptic transmission. J Physiol Paris 89:77-81. CrossRef Medline

Meinrenken CJ, Borst JG, Sakmann B (2002) Calcium secretion coupling at calyx of held governed by nonuniform channel-vesicle topography. J Neurosci 22:1648-1667. Medline

Nouvian R (2007) Temperature enhances exocytosis efficiency at the mouse inner hair cell ribbon synapse. J Physiol 584:535-542. CrossRef Medline

Oertner TG, Sabatini BL, Nimchinsky EA, Svoboda K (2002) Facilitation at single synapses probed with optical quantal analysis. Nat Neurosci 5:657664. CrossRef Medline

Otsu Y, Bormuth V, Wong J, Mathieu B, Dugué GP, Feltz A, Dieudonné S (2008) Optical monitoring of neuronal activity at high frame rate with a digital random-access multiphoton (RAMP) microscope. J Neurosci Methods 173:259-270. CrossRef Medline

Padua RA, Wan WH, Nagy JI, Geiger JD (1991) [3H]ryanodine binding sites in rat brain demonstrated by membrane binding and autoradiography. Brain Res 542:135-140. CrossRef Medline

Pelkey KA, Topolnik L, Lacaille JC, McBain CJ (2006) Compartmentalized $\mathrm{Ca}^{2+}$ channel regulation at divergent mossy-fiber release sites underlies target cell-dependent plasticity. Neuron 52:497-510. CrossRef Medline

Pernía-Andrade AJ, Jonas P (2014) Theta-gamma-modulated synaptic currents in hippocampal granule cells in vivo define a mechanism for network oscillations. Neuron 81:140-152. CrossRef Medline

Petukhov VV, Popov VI (1986) Quantitative analysis of ultrastructural changes in synapses of the rat hippocampal field CA3 in vitro in different functional states. Neuroscience 18:823-835. CrossRef Medline

Pinheiro PS, Perrais D, Coussen F, Barhanin J, Bettler B, Mann JR, Malva JO, Heinemann SF, Mulle C (2007) GluR7 is an essential subunit of presynaptic kainate autoreceptors at hippocampal mossy fiber synapses. Proc Natl Acad Sci U S A 104:12181-12186. CrossRef Medline

Qiu DL, Knöpfel T (2009) Presynaptically expressed long-term depression at cerebellar parallel fiber synapses. Pflugers Arch 457:865-875. CrossRef Medline

Quinlan ME, Hirasawa M (2013) Multivesicular release underlies short term synaptic potentiation independent of release probability change in the supraoptic nucleus. PLoS One 8:e77402. CrossRef Medline

Regehr WG, Delaney KR, Tank DW (1994) The role of presynaptic calcium in short-term enhancement at the hippocampal mossy fiber synapse. J Neurosci 14:523-537. Medline

Reid CA, Clements JD (1999) Postsynaptic expression of long-term potentiation in the rat dentate gyrus demonstrated by variance-mean analysis. J Physiol 518:121-130. CrossRef Medline

Reid CA, Dixon DB, Takahashi M, Bliss TV, Fine A (2004) Optical quantal analysis indicates that long-term potentiation at single hippocampal mossy fiber synapses is expressed through increased release probability, recruitment of new release sites, and activation of silent synapses. J Neurosci 24:3618-3626. CrossRef Medline

Rollenhagen A, Sätzler K, Rodríguez EP, Jonas P, Frotscher M, Lübke JH (2007) Structural determinants of transmission at large hippocampal mossy fiber synapses. J Neurosci 27:10434-10444. CrossRef Medline

Rusakov DA (2006) Ca2+-dependent mechanisms of presynaptic control at central synapses. Neuroscientist 12:317-326. CrossRef Medline 
Rusakov DA, Kullmann DM (1998) Extrasynaptic glutamate diffusion in the hippocampus: ultrastructural constraints, uptake, and receptor activation. J Neurosci 18:3158-3170. Medline

Salin PA, Scanziani M, Malenka RC, Nicoll RA (1996) Distinct short-term plasticity at two excitatory synapses in the hippocampus. Proc Natl Acad Sci U S A 93:13304-13309. CrossRef Medline

Salomé R, Kremer Y, Dieudonné S, Léger JF, Krichevsky O, Wyart C, Chatenay D, Bourdieu L (2006) Ultrafast random-access scanning in twophoton microscopy using acousto-optic deflectors. J Neurosci Methods 154:161-174. CrossRef Medline

Satake S, Inoue T, Imoto K (2012) Paired-pulse facilitation of multivesicular release and intersynaptic spillover of glutamate at rat cerebellar granule cell-interneurone synapses. J Physiol 590:5653-5675. CrossRef Medline

Sätzler K, Söhl LF, Bollmann JH, Borst JG, Frotscher M, Sakmann B, Lübke JH (2002) Three-dimensional reconstruction of a calyx of Held and its postsynaptic principal neuron in the medial nucleus of the trapezoid body. J Neurosci 22:10567-10579. Medline

Scheuss V, Neher E (2001) Estimating synaptic parameters from mean, variance, and covariance in trains of synaptic responses. Biophys J 81:19701989. CrossRef Medline

Scheuss V, Schneggenburger R, Neher E (2002) Separation of presynaptic and postsynaptic contributions to depression by covariance analysis of successive EPSCs at the calyx of held synapse. J Neurosci 22:728-739. Medline

Schmitz D, Mellor J, Nicoll RA (2001) Presynaptic kainate receptor mediation of frequency facilitation at hippocampal mossy fiber synapses. Science 291:1972-1976. CrossRef Medline

Schneggenburger R, Meyer AC, Neher E (1999) Released fraction and total size of a pool of immediately available transmitter quanta at a calyx synapse. Neuron 23:399-409. CrossRef Medline

Schneggenburger R, Sakaba T, Neher E (2002) Vesicle pools and short-term synaptic depression: lessons from a large synapse. Trends Neurosci 25: 206-212. CrossRef Medline

Scott R, Rusakov DA (2006) Main determinants of presynaptic Ca2+ dynamics at individual mossy fiber-CA3 pyramidal cell synapses. J Neurosci 26:7071-7081. CrossRef Medline

Scott R, Lalic T, Kullmann DM, Capogna M, Rusakov DA (2008) Target-cell specificity of kainate autoreceptor and $\mathrm{Ca} 2+$-store-dependent shortterm plasticity at hippocampal mossy fiber synapses. J Neurosci 28: 13139-13149. CrossRef Medline

Shimizu H, Fukaya M, Yamasaki M, Watanabe M, Manabe T, Kamiya H
(2008) Use-dependent amplification of presynaptic Ca2 + signaling by axonal ryanodine receptors at the hippocampal mossy fiber synapse. Proc Natl Acad Sci U S A 105:11998-12003. CrossRef Medline

Spirou GA, Chirila FV, von Gersdorff H, Manis PB (2008) Heterogeneous $\mathrm{Ca} 2+$ influx along the adult calyx of held: a structural and computational study. Neuroscience 154:171-185. CrossRef Medline

Sugimori M, Lang EJ, Silver RB, Llinas R (1994) High-resolution measurement of the time course of calcium-concentration microdomains at squid presynaptic terminals. Biological Bull 187:300-303. CrossRef

Taschenberger H, Leão RM, Rowland KC, Spirou GA, von Gersdorff H (2002) Optimizing synaptic architecture and efficiency for highfrequency transmission. Neuron 36:1127-1143. CrossRef Medline

Tong G, Jahr CE (1994) Multivesicular release from excitatory synapses of cultured hippocampal neurons. Neuron 12:51-59. CrossRef Medline

Toth K, Suares G, Lawrence JJ, Philips-Tansey E, McBain CJ (2000) Differential mechanisms of transmission at three types of mossy fiber synapse. J Neurosci 20:8279-8289. Medline

Tzounopoulos T, Janz R, Südhof TC, Nicoll RA, Malenka RC (1998) A role for cAMP in long-term depression at hippocampal mossy fiber synapses. Neuron 21:837-845. CrossRef Medline

Urban NN, Henze DA, Barrionuevo G (2001) Revisiting the role of the hippocampal mossy fiber synapse. Hippocampus 11:408-417. CrossRef Medline

von Kitzing E, Jonas P, Sakmann B (1994) Quantal analysis of excitatory postsynaptic currents at the hippocampal mossy fiber-CA3 pyramidal cell synapse. Adv Second Messenger Phosphoprotein Res 29:235-260. CrossRef Medline

Vyleta NP, Jonas P (2014) Loose coupling between Ca2+ channels and release sensors at a plastic hippocampal synapse. Science 343:665-670. CrossRef Medline

Wadiche JI, Jahr CE (2001) Multivesicular release at climbing fiberPurkinje cell synapses. Neuron 32:301-313. CrossRef Medline

Watanabe J, Rozov A, Wollmuth LP (2005) Target-specific regulation of synaptic amplitudes in the neocortex. J Neurosci 25:1024-1033. CrossRef Medline

Yasuda R, Nimchinsky EA, Scheuss V, Pologruto TA, Oertner TG, Sabatini BL, Svoboda K (2004) Imaging calcium concentration dynamics in small neuronal compartments. Sci STKE 2004:p15. CrossRef

Zucker RS, Regehr WG (2002) Short-term synaptic plasticity. Annu Rev Physiol 64:355-405. CrossRef Medline 